\title{
Criteria weighting for green technology selection as part of retrofit decision making process for existing non-domestic buildings
}

\author{
Jin Si ${ }^{*}$, Ljiljana Marjanovic-Halburd \\ UCL Institute for Environmental Design and Engineering, the Bartlett, University College London, Central \\ House, 14 Upper Woburn Place, London WC1H ONN
}

\begin{abstract}
The implementation of green technologies, as part of retrofit, can significantly improve building performance. However, green technology selection is a complex decision making process due to multiple evaluation criteria and often conflicting interests of different stakeholders involved. This paper proposes default criteria weights based for previously-developed criteria tree consisting of in total 39 criteria organised around environmental, economic, social and technical performance of green technologies. Web-based surveys of experts including architects, engineers, planners in the UK and China were conducted to capture expert opinions on sustainability and technical criteria. Analytical Hierarchy Process (AHP) method was used to calculate default criteria weights. Comparisons between expert groups in different countries were also performed. Results show that UK experts more concern about Economic performance of green technology, specifically with UK architects and engineers assigning high weights on Cost. For the Environmental category, Reduction of energy consumption and Reduction of water consumption are ranked as the most important topics under In-use environmental performance by all experts. UK experts have shown a growing concern on Reduction of water consumption. Under The improvement of indoor environmental quality, Thermal comfort is ranked as the most important criterion by UK experts and Visual comfort is weighted as the first priority by Chinese experts. Compared with UK experts, Chinese experts have placed a significant importance on Technical criteria, represented by engineer group emphasising on Durability for this category.
\end{abstract}

Keywords: Non-domestic building retrofit; Decision making process; Criteria weighting; Analytical Hierarchy Process (AHP) method

\section{Introduction}

With increased awareness of environmental pollution, natural resource depletion and social issues, sustainable development has become a growing concern throughout the world [1]. At the same time, buildings have been identified as one of the heaviest consumers of natural resources, accounting for $40 \%$ of global energy use, $30 \%$ of energy-related GHG emissions, approximately $12 \%$ of water use and nearly $40 \%$ of waste [2]. For buildings to be more environmental friendly, there is a need to reduce energy and water consumption during operation and take advantage of recycling opportunities at the end of the building life cycle [3].

\footnotetext{
* Corresponding author. UCL Institute for Environmental Design and Engineering, the Bartlett, University College London, Central House, 14 Upper Woburn Place, London WC1H ONN Email address: j.si.12@alumni.ucl.ac.uk
} 
Apart from environment, buildings can affect occupant productivity and business profitability [4] as well as human wellbeing and community engagement [5].

Building performance can incorporate performance in Energy Efficiency, Water Efficiency, Indoor Enviromental Quality and health and wellbeing[6]. Whilst improvement in environmental performance of new buildings is primarily driven through legislative efforts, existing buildings often require retrofits to improve their environmental or sustainable performance. Environmental, economic, social and technical implications of building retrofits have been investigated through several studies [7-9]. Green technologies such as efficient lighting, PV panels and monitoring systems have proved to improve the building performance to a certain level. $[10,11]$

The findings indicate that existing building retrofits can offer significant opportunities for improving overall sustainability performance [12-15]. Despite the fact that improved performance through building retrofits was demonstrated for non-domestic buildings $[16,17]$, research on domestic building stock is still dominant.

There is a wide range of green technologies readily available for retrofit projects. However, the decision as to which green technology should be selected is a complex decision making process subjective to several technological alternatives, multiple decision criteria and different stakeholder perspectives [18-20]. Whilst ultimate goals of sustainable development can be considered universal, the sustainable construction has different approaches and different priorities in different countries[18] and the refurbishment part of construction industry is not the exception. In addition to economic and social differences number of other variables and their importance vary from country to country. Agenda 21 on sustainable construction [22] fully recognised that activities within the construction sector driven by sustainable development agenda will be effected by local constructs such as professional practice, nature of building stock, level of industrial development.

Moreover, the stakeholders from different backgrounds may have contrasting opinions which can influence the final decision [20,23]. Multi-Criteria Decision Making (MCDM) methods have been successfully used in selecting green technologies for buildings [20,24]. The MCDM decision-making process consists of four steps: criteria development, criteria weighting, alternatives scoring and results synthesis. Criteria weighting is one of the crucial steps allowing a trade-off between multiple decision criteria and a balance between different stakeholder perspectives $[23,25]$. As criteria weights can directly influence the ranking order of alternatives and the final results [18], defining them whilst taking into account different stakeholder perspectives is essential.

This paper aims at providing default criteria weights for previously developed decision criteria for green technology selection in non-domestic building retrofits [26]. The default criteria weights would correspond to general preferences of relevant built environment professionals involved in retrofit projects operating in two distinctly different national contexts: UK and China. The research mainly adopts a survey approach to collect expert opinions from UK and China. The Analytical Hierarchy Process (AHP) method is used to calculate criteria weights for expert groups at each national level as well as for different professional backgrounds (architects, engineers, etc.) and comparison between groups is performed. The paper is organised as: Section 2 presents a review of weighting methods and existing 
research. Section 3 describes the research methodology. Section 4 presents criteria weights results for all experts surveyed as well as for different professional background (architect group and engineer group) and national groups (UK and China) and summarises the results and states the research limitations. Section 5 concludes with main findings.

\section{Approaches to criteria weighting}

Weighting methods are classified into equal weighting and rank-order weighting [27]. In equal weighting, criteria weights are equally assigned and weighted with the average value of one, which does not require stakeholder preferences. In rank-order weighting, criteria weights are distributed and influenced by stakeholder perspectives. Rank-order weighting methods include objective weighting method, subjective weighting method and combination weighting method [18]. Objective weighting method is characterised by mathematical models, complex calculation process and intensive data requirement [28] and is not often used [29]. Subjective weighting method relies on informing criteria weights directly from stakeholders by interviewing or questionnaire. Combination weighting method is used to balance merits and limitations of objective and subjective weighting methods, but the process is complex and not widely-used [18].

Current research has seen a wide use of subjective weighting methods. Typical subjective weighting methods include Simple Multi-Attribute Rating Technique (SMART), Swing method and Pair-wise comparison methods. In SMART, decision makers assign 10 points to the least important criteria and then add points up to 100 when the importance increases [30]. Swing method is to ask decision makers to assign 100 points to the criteria with the highest expectation for significant improvements. Fewer points are then given to the next alternative. Pair-wise comparison method is comparing the importance between two criteria [31]. The analytic hierarchy process (AHP) is one of pair-wise comparison methods which uses a 9 point scale to compare criteria relative importance. Since individual judgements can never agree perfectly, the degree of consistency achieved in the pairwise comparison is measured by the consistency ratio [32]. Saaty [33] advocates the use of consensus by voting to reach at a common pairwise comparison matrix or by aggregating individual judgments using the geometric mean of individual pairwise comparison matrix. The former approach is applicable when the members can meet as a group. The latter one can be used when group meeting is not applicable [34].

Chen et al. [35] used industry wide survey to determine the relative importance of 33 proposed sustainable performance criteria for construction method selection in concrete buildings. The survey has been designed to collect perceptions of experienced practitioners on the importance of the proposed criteria. A scale of 1-5 (where 1 is 'least important' and 5 'extremely important') was used for criteria weighting. The 5 point scale was used by Menassa and Baer [36] who developed a model to synthesise stakeholder opinions and determine the technical importance of retrofit measures against stakeholder requirements. They proposed 30 potential stakeholder requirements as decision criteria and the importance of them is suggested to be measured on a scale of 1 to 5 (from "not important" to "extremely important"). 
Pan et al. [19] proposed the decision criteria for building system selection in housing and quantified their relative importance. Decision criteria are initially compiled through literature review and confirmed with relevant stakeholders through semi-structured interviews. Criteria weighting was then determined during the one-day workshop. Several weighting techniques including direct rating, the point allocation, and AHP were provided to the workshop attendees for flexible use.

Zainab et al. [23] investigated decision criteria and their weights for the selection of sustainable technologies for retail buildings retrofits from the perspective of different stakeholders involved. A two-stage approach was adopted: the initial stage was to identify decision criteria with stakeholders using semi-structured interviews; the second stage was to invite stakeholders to complete AHP questionnaires during a one-day workshop, where the method and the importance of consistent judgement was explained to participants.

Banville et al.[37] described a stakeholder as everyone with a vested interest in a problem that can either affect, be affected by or is both being affected by and affecting the problem. In the context of green technology selection, stakeholders can have different backgrounds: architecture, design, engineering, planning, management, economy. Rey [38] proposed a multi-criteria assessment methodology for existing building retrofits, which simultaneously takes environmental, social, and economic criteria into account to support the decision making process. The author emphasised that varying stakeholder opinions have a great importance in the selection of the most suitable retrofit strategy, and collaboration between stakeholders is required. Several studies indicate that conflicting stakeholder perspectives are the main barrier in the decision making of sustainable retrofits $[39,40]$.

Apart from professional backgrounds, criteria weighting can also be influenced by local or national contexts. Relevant research can be found for criteria development for different countries but they have not focused enough on rank-order weighting. For instance, Huang et al. [41] has found that in China, at the national level, green technology selection mainly emphasised microeconomic efficiency and contribution to industrial development under Economy criteria; GHG emission reduction, contribution to the industrial development and land resources under Environment and Energy criteria; employment generation and technology safety under Society criteria. The equal weighting method was used in this research when integrating technology performance scores. The importance of regional or national context was also identified within wider debate about green building performance assessment process [42]. Whilst sustainability criteria are universally relevant, a variation in relative importance of the criteria is context dependent. And that relevant importance is reflected through weighting systems.

\section{Research design}

Previous Chapter demonstrated that criteria weighting is an important step in decision making process; from those dealing with construction methods choice, building systems or sustainable technology selection. Whilst decision criteria are usually compiled through literature review and in addition may be verified with stakeholders in interviews or workshops $[19,36]$, criteria weighting can be conducted by interviews, workshops or questionnaires. 
Direct weighting or pairwise comparison weighting with AHP method, although commonly applied $[19,23]$ is still limited in the field of green technology selection for non-domestic building retrofits. As this research aims to collect general preferences from industry professionals towards multiple criteria regarding green technology selection in building retrofits at two different national locations, a web-based survey was deployed. The survey is built upon an already-proposed criteria tree [26]. This criteria tree consists of economic, environmental, social and technical criteria (see Figure 1) which are organised from general criteria to specific sub-criteria and some of which are quantitative whilst other are qualitative. The industry wide survey and subsequent statistical analysis of the survey data lead to a development of default weights for these criteria.

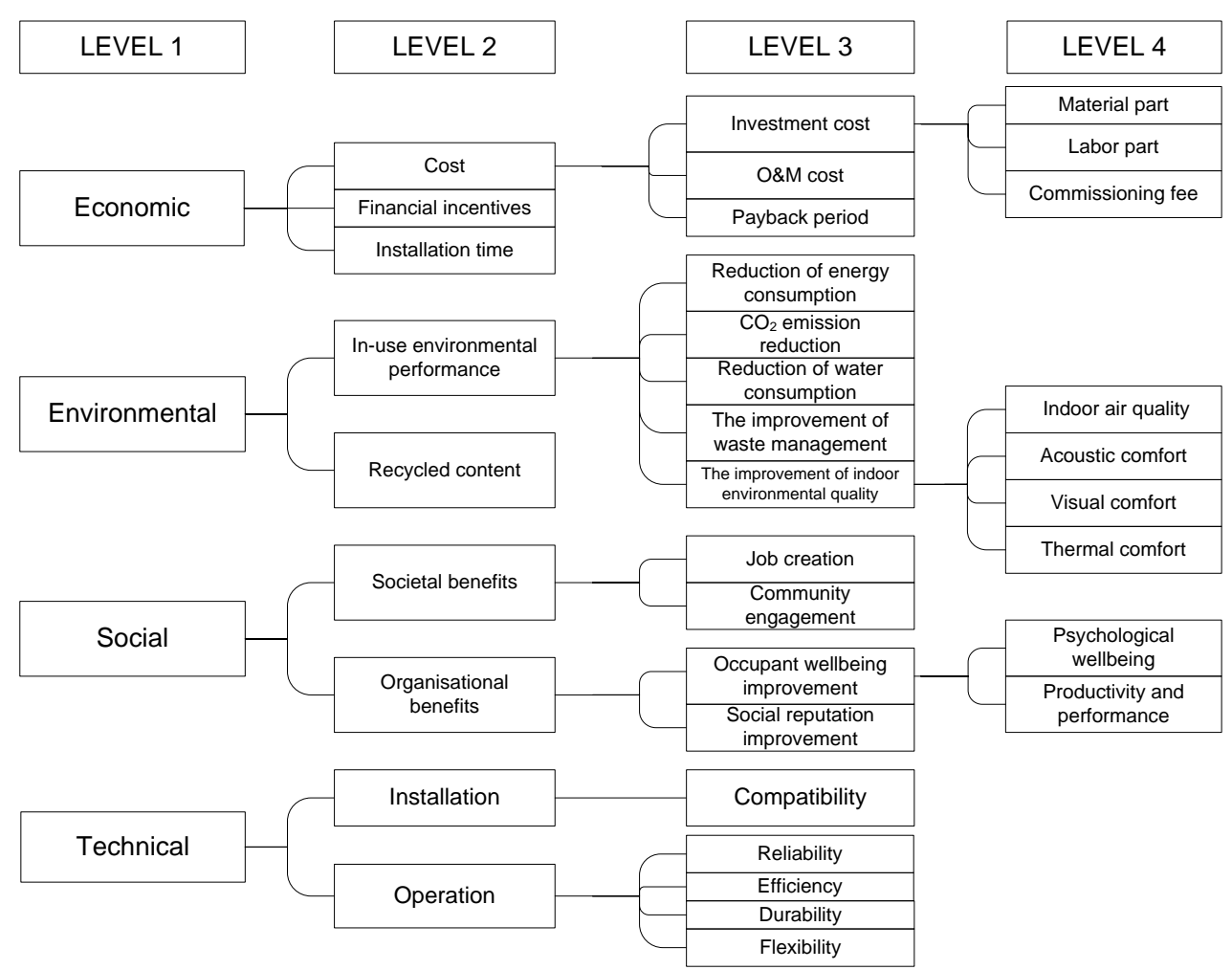

Figure 1 Integrated AHP hierarchy with multiple criteria [26]

The survey design in general includes four steps: survey sampling, question design, pilot survey and final survey. The nature of research implied the need for purposive sampling where participants are chosen base on their professional experience in non-domestic building retrofit projects. In order to ensure inclusion of relevant participants as well as a diversity within targeted population a multi-stage sampling method is adopted. Figure 2 illustrates the multi-stage sampling strategy: step 1) to identify professional groups in the field of built environment; step 2) to determine expert groups who have working experience in the building retrofit; step 3 ) to select individual experts to be the final sample. 


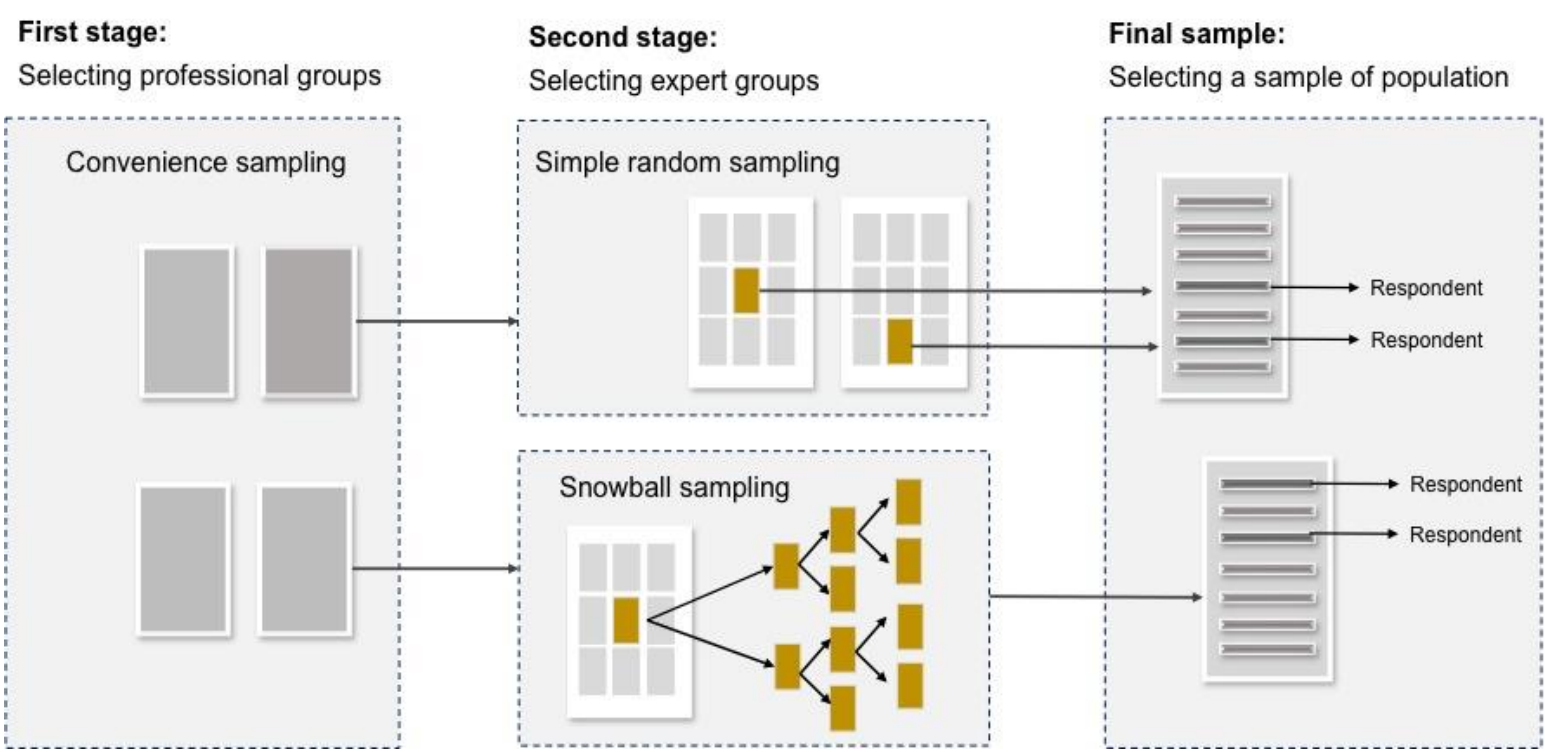

Figure 2 Multi-stage sampling strategy (adapted from [43])

Targeted professional groups at Stage 1 are listed in Table 1. In the second stage, two sampling methods are applied: Simple random sampling method and Snowball sampling method $[44,45]$ in order to maximise the reach. The response rate is not easy to calculate because the size of expert groups cannot be calculated.

Table 1 Targeted professional groups

\begin{tabular}{ll}
\hline Country & \multicolumn{1}{c}{ Professional groups } \\
\hline \multirow{3}{*}{ UK } & MSc Environmental design and Engineering alumni \\
& community \\
& Industry corporation intranet \\
& Linkedln Connections \\
\cline { 2 - 2 } & Total \\
\hline \multirow{3}{*}{ China } & Institutes of Architectural Design personal connection \\
& Industry corporation intranet \\
& Higher Education personal connection \\
\cline { 2 - 2 } & Total \\
\hline
\end{tabular}

The survey questions have been divided into three groups:

1. Respondents' relevant professional experience;

2. Further criteria development;

3. Criteria weighting for existing criteria.

Open-format question is used to collect the suggestion for further criteria tree development as below: "Is there any criterion you want to add? If so, please also indicate its parent criterion on the existing tree. [For example: Environmental (Ecosystem impacts)]" However as the analysis of received responses go beyond the aim of this paper they are not featuring in the analysis of the results. The full set of responses to this group of questions 
can be found in [46].

The third group of questions which aims to inform criteria weighting is based on a 1-9 scale developed by Saaty [32]. The clarity of scale design is important for survey respondents who are not familiar with the AHP method to comprehend the principle. The purpose of the scale is to show the relative importance of the criteria immediately, which enables the respondents to provide their opinions directly instead of spending time on figuring out the meanings of scale values. Figure 3 illustrates the design of criteria weighting question.

The way the scale is used is demonstrated below for the example of comparing the relative importance of Economic and Environmental criteria.

\begin{tabular}{|c|c|c|c|c|c|c|c|c|c|}
\hline & \multicolumn{3}{|l|}{$\begin{array}{l}\text { Extremely } \\
\text { Important }\end{array}$} & \multicolumn{2}{|c|}{$\begin{array}{c}\text { Equally } \\
\text { important }\end{array}$} & \multicolumn{4}{|c|}{$\begin{array}{c}\text { Extremely } \\
\text { important }\end{array}$} \\
\hline & 9 & 7 & 5 & 1 & 3 & 5 & 7 & 9 & \\
\hline Economic & & & & & & 1 & 1 & \multicolumn{2}{|c|}{ Environmental } \\
\hline \multirow{3}{*}{$A$ vs $B$} & \multicolumn{4}{|c|}{$A$ is more important than $B$} & & \multicolumn{4}{|c|}{ B is more important than $A$} \\
\hline & $\begin{array}{c}\text { Extremely } \\
\text { more } \\
\text { important }\end{array}$ & $\begin{array}{c}\text { Very } \\
\text { strongly } \\
\text { more } \\
\text { important } \\
\end{array}$ & $\begin{array}{c}\text { Strongly } \\
\text { more } \\
\text { important }\end{array}$ & $\begin{array}{c}\text { Moderately } \\
\text { more } \\
\text { important }\end{array}$ & $\begin{array}{c}\text { Equally } \\
\text { important }\end{array}$ & $\begin{array}{c}\text { Moderately } \\
\text { more } \\
\text { important }\end{array}$ & $\begin{array}{c}\text { Strongly } \\
\text { more } \\
\text { important }\end{array}$ & $\begin{array}{c}\text { Very } \\
\text { strongly } \\
\text { more } \\
\text { important }\end{array}$ & $\begin{array}{c}\text { Extremely } \\
\text { more } \\
\text { important }\end{array}$ \\
\hline & $A \gg \gg>B$ & $A \gg>B$ & $A \gg>B$ & $A>B$ & $A=B$ & $A<B$ & $A<<B$ & $A<<<B$ & $A \ll<<<B$ \\
\hline $\begin{array}{l}\text { [A] Economic/ } \\
\text { [B]Environmental }\end{array}$ & 0 & 0 & $\odot$ & 0 & 0 & 0 & 0 & 0 & 0 \\
\hline
\end{tabular}

Figure 3 An example of criteria weighting question

The survey is initially designed in a paper version and tested within a group of 10 researchers working at UCL's Institute of Environmental Design and Engineering. Three feedback questions were individually asked when they returned the survey:

1. How long did it take you to complete the survey?

2. Did you find any questions ambiguous or difficult to answer?

3. Is there any difficulty to understand the method doing criteria weighting?

All the participants in the the pilot study thought that questions are well developed and generally easy to understand, but a total of 43 pairwise comparisons might take a long time to answer and thus affect the number of returns. They suggested that clear and concise explanation of technical criteria in the criteria tree is provided.

Based on the feedback, the survey has been improved by providing definitions for technical criteria of compatibility and flexibility. The full survey can be found in [46]. The paper version survey is then designed into formal web-based survey using survey design tools. Google form is used for English version, and the survey design tool called "Sojump" is used for the Chinese version. Survey links are generated and sent to professional groups listed in Table 1. 
The data collection took approximately two months for each country. For the UK, the survey circulation and data collection were conducted from November-2015 to January-2016. For China, this was from January-2016 to February-2016. All the data collected was organised in the format of Excel sheet for further statistical analysis.

Descriptive analysis methods are used to analyse sample characteristics. Criteria weights are calculated in three steps:

1) composition of matrices of pairwise comparison (MPC);

2) consistency checking for MPC;

3) criteria weights derivation using AHP method [47].

This 3-step process is applied to each criteria weighting question and all expert groups. The geometric mean of individuals' judgements is used for criteria weights calculation for different expert groups. Aczel and Saaty [48] have shown that the geometric mean is uniquely appropriate for combining individual judgements because of its preservation of the property of the judgement matrix.

\section{Results}

\subsection{Respondents' professional experience}

After circulating the survey link to targeted professional groups, a total of 54 valid responses were received, 25 from the UK and 29 from China. As sample size is relevant only when research goal is to provide estimates or statistically significant discriminatory variable, the obitaned sample size can be described as being within the acceptable range[49].

The responses in relation to their professional background indicate that the engineering background was dominant for both UK (48.6\%) and China (41.4\%) professionals followed by architecture abckground ( $42.9 \%$ in the UK and $31 \%$ in China). UK respondents who selected "others" background (8.6\%) are mainly from ecology and environmental consultancy. In addition to architectural background, $13.8 \%$ of Chinese respondents have planning background and $6.9 \%$ design background. Chinese respondents who selected "Others" background (6.9\%) are from safety assessment.

Figure 4 shows respondents' s expertise distribution. The dominant groups are those with the expertise in structure engineering and façade engineering for both Chinese and UK expert groups.

Based on the collected survey responses, $86 \%$ of survey respondents have more than 3 years of working experience in built environment and the majority had been involved in several retrofit projects [46]. 

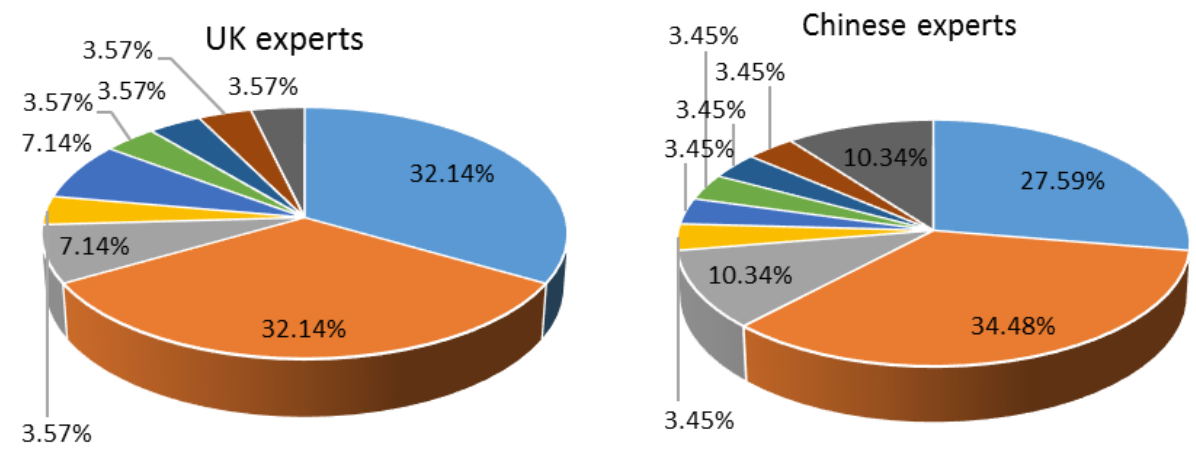

$$
\begin{aligned}
& \text { - Façade Engineering } \\
& \text { - Structure Engineering } \\
& \text { - Mechnical, Eletrical and Plumbing } \\
& \text { - Facility management } \\
& \text { - Energy analysis } \\
& \text { - Ecology } \\
& \text { - LEED or BREEAM Certification } \\
& \text { - Sustainability consulting } \\
& \text { - Others }
\end{aligned}
$$

Figure 4 The expertise distribution of the survey respondents

Table 2 presents the difference between the most frequent client requirements in the UK and China. The most frequent client requirements in the UK are "to reduce the operational cost", "to improve energy performance" and "to increase asset value". In China, the most frequent client requirements are "to improve building safety and security", "to reduce operational cost" and "to improve occupant well-being".

Table 2 Comparison of the the most frequent client requirements in the UK and China

\begin{tabular}{ccc}
\hline Client requirements & UK & China \\
\hline To reduce operational cost & $62.90 \%$ & $48.48 \%$ \\
To increase asset value & $42.90 \%$ & $12.12 \%$ \\
To improve energy performance & $60.00 \%$ & $30.30 \%$ \\
To improve water efficiency & $20.00 \%$ & $9.09 \%$ \\
To improve occupant wellbeing & $31.40 \%$ & $42.42 \%$ \\
To improve building durability & $20.00 \%$ & $18.18 \%$ \\
To conserve fabric (heritage building) & $28.60 \%$ & $21.21 \%$ \\
To improve building safety \& security & $8.60 \%$ & $48.48 \%$ \\
To improve corporate sustainability & $17.10 \%$ & $18.18 \%$ \\
Others & $14.30 \%$ & $6.06 \%$ \\
\hline
\end{tabular}




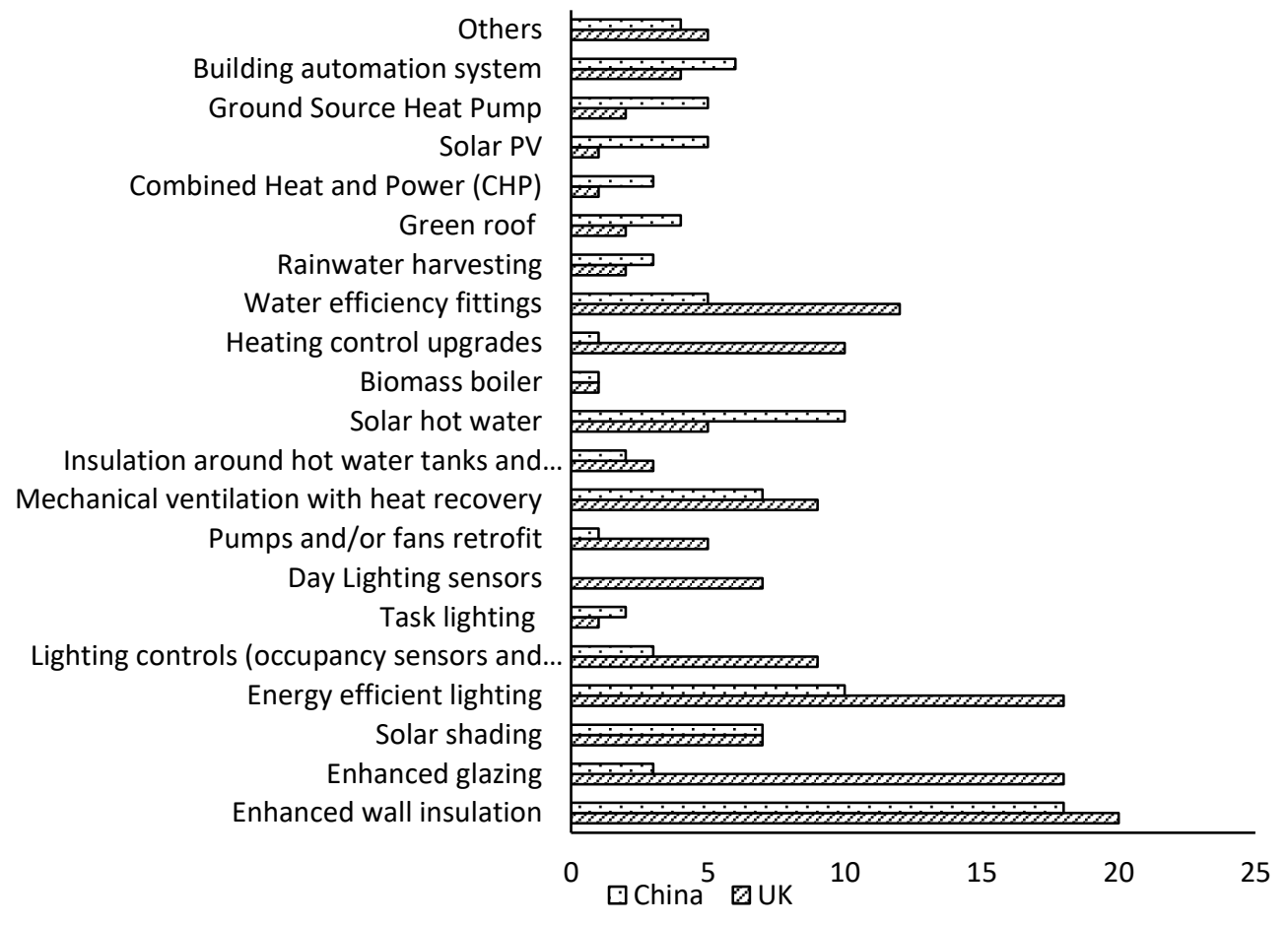

Figure 5 Comparison of the most commonly-used green technologies from the UK and China

The results presented in Figure 5 show that in the UK, the most commonly used green technologies in retrofit projects are Energy efficient lighting, Enhanced wall insulation, and Enhanced glazing. In China, the most commonly used green technologies are Enhanced wall insulation, Energy efficient lighting and Solar hot water. The results also indicate that control technologies such as Heating control upgrades, Daylighting sensors, Pumps and/or fans retrofit and Water efficiency fittings are not frequently used in the retrofit projects in both UK or China. However, the Building automation system has been given considerable attention during retrofit projects in China.

\subsection{Criteria weighting group of questions}

The respondents were first asked to rank the importance of all Level 1 criteria: environmental, economic, social and technical (see Figure 1). They were then asked to rank criteria at the next level within each individual group. For example, at Level 2 Economic criterion, experts were asked to rank the criteria of Cost, Financial incentives and Installation time. The same process was repeated for all levels of the existing criteria tree. All responses received were tested for consistency. For example, if Economic is weighed more important than Environmental, and Environmental is weighed more important than Social, then if Economic is preferable over Social the judgment is considered to be consistent. Instead, if Social is weighed more important than Economic, the judgement is inconsistent. Results of all the Matrices of Pairwise Comparison (MPC) that passed consistency checking are listed in Appendix A. The number of MPC for each level that passed consistency checking is listed in Table A.1. The consistency ratio is listed in Table A.2. Group weighting values for decision 
criteria at Level 1 and 2 are presented in Table 3. The default weights for all levels of criteria are shown in Appendix $B$.

Table 3 Group weighting values given by the UK and Chinese groups for Level 1 and 2 of criteria tree

\begin{tabular}{|c|c|c|c|c|c|c|c|}
\hline \multirow{2}{*}{ Criteria } & \multirow{2}{*}{ Sub-criteria } & \multicolumn{3}{|c|}{ UK } & \multicolumn{3}{|c|}{ China } \\
\hline & & All & Architects & Engineers & All & Architects & Engineers \\
\hline \multirow{4}{*}{ Level 1} & Economic & 0.296 & 0.173 & 0.326 & 0.190 & $0.250^{\star}$ & 0.189 \\
\hline & Environmental & 0.279 & 0.303 & 0.289 & 0.290 & $0.250^{*}$ & 0.282 \\
\hline & Social & 0.185 & 0.303 & 0.152 & 0.181 & $0.250^{*}$ & 0.248 \\
\hline & Technical & 0.240 & 0.220 & 0.234 & 0.338 & $0.250^{*}$ & 0.282 \\
\hline \multirow{3}{*}{$\begin{array}{c}\text { Level } 2 \\
\text { (Economic) }\end{array}$} & Cost & 0.465 & 0.405 & 0.504 & 0.467 & $0.515^{\star}$ & 0.333 \\
\hline & $\begin{array}{l}\text { Financial } \\
\text { incentives }\end{array}$ & 0.304 & 0.405 & 0.234 & 0.226 & $0.097^{*}$ & 0.333 \\
\hline & Installation time & 0.231 & 0.189 & 0.262 & 0.306 & $0.388^{*}$ & 0.333 \\
\hline \multirow[t]{2}{*}{$\begin{array}{c}\text { Level } 2 \\
\text { (Environment } \\
\text { al) }\end{array}$} & $\begin{array}{l}\text { In-use } \\
\text { environmental } \\
\text { performance }\end{array}$ & 0.665 & 0.646 & 0.670 & 0.577 & 0.539 & 0.590 \\
\hline & Recycled content & 0.335 & 0.354 & 0.330 & 0.423 & 0.461 & 0.410 \\
\hline \multirow{2}{*}{$\begin{array}{l}\text { Level } 2 \\
\text { (Social) }\end{array}$} & Societal benefits & 0.521 & 0.545 & 0.534 & 0.543 & 0.567 & 0.528 \\
\hline & $\begin{array}{c}\text { Organisational } \\
\text { benefits }\end{array}$ & 0.479 & 0.455 & 0.466 & 0.457 & 0.433 & 0.472 \\
\hline \multirow{2}{*}{$\begin{array}{c}\text { Level } 2 \\
\text { (Technical) }\end{array}$} & Installation & 0.475 & 0.452 & 0.506 & 0.525 & 0.580 & 0.516 \\
\hline & Operation & 0.525 & 0.548 & 0.494 & 0.475 & 0.420 & 0.484 \\
\hline
\end{tabular}

* Singular response that has passed the consistency checking.

When criteria weighting is conducted in semi-interviews or workshop, consistent judgements from participants can be easier to manage $[19,23]$. When the criteria weighting is conducted through Expert Choice, a software professionally designed for AHP method, a reminder of inconsistency can be triggered. The number of MPC that can pass consistency checking may be adjusted when using a different CR threshold value. In this study, we adopted a standard CR threshold value of 0.10 which has been widely used as a measure of the consistency checking of AHP applications in literature.

\subsection{Criteria weights comparison}

\subsubsection{Criteria weighting within the individual country}

As demonstrated in the Introduction, criteria weighting can be influenced by stakeholder perspectives. In this section a comparison of criteria weights by levels between expert groups within each country was performed. The default weights for Level 1 criteria in relation to a stakeholder background is presented in Figure 6 for the UK and Chinese experts respectively. 


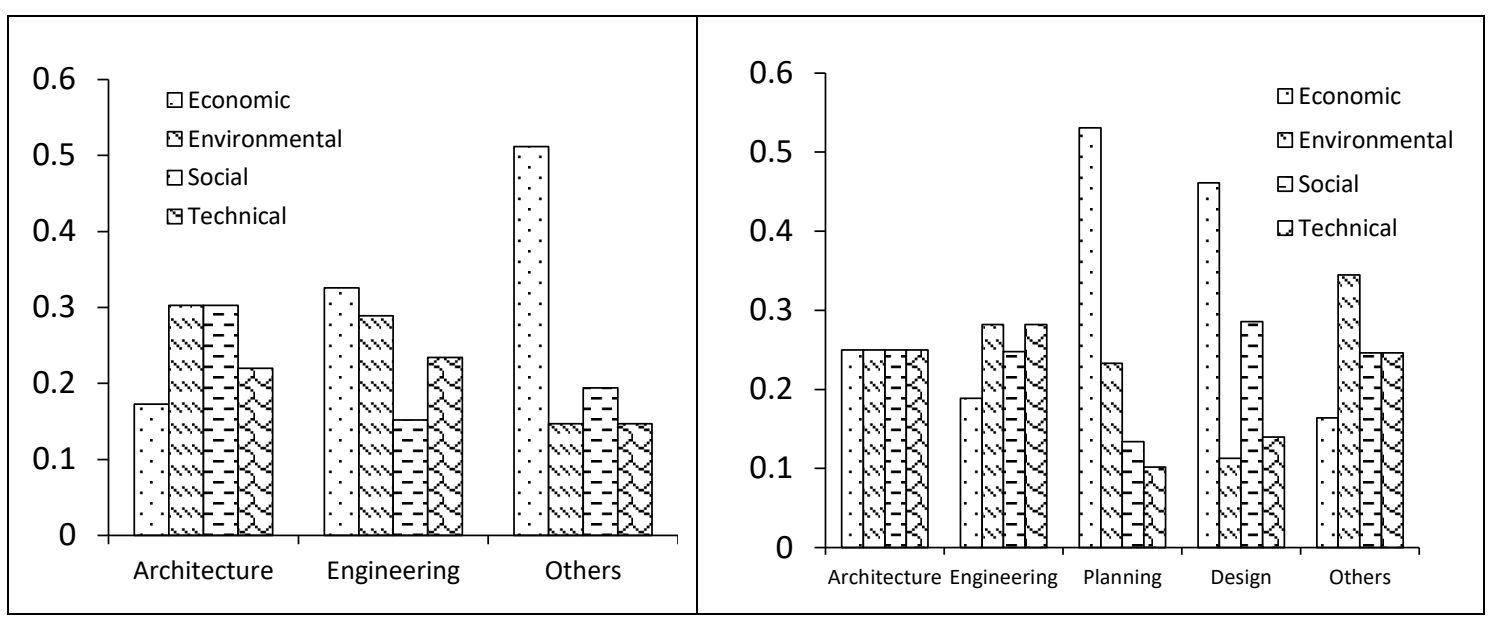

Figure 6 Comparison of Level 1 criteria by expert groups with different background in the UK (graph on the left hand side) and in China (graph on the right hand side)

In the UK, for Level 1 criteria, the architect group have assigned the highest weighting factors to Environmental and Social criteria whilst they regard Economic criterion as the least important criterion. The engineer group has assigned weighting factors from highest to lowest, to Economic, Environmental, Technical and Social criteria. The expert group from other backgrounds regard the Economic criterion as the most important criterion as well followed by Social criterion whilst the other two criteria were rated to be of equal importance but less important than Economic and Social criterion.

The results presented in Figure 6 indicate that Chinese architects consider all Level 1 criteria (Economic, Environmental, Social and Technical) equally important. Chinese engineers give slight advantage to Environmental and Technical criteria whilst those with planning and design background clearly put economic criterion above all others. Designers also highly value Social criterion.

The default weights for Level 2 criteria in relation to a stakeholder background is presented in Figures 7 and 8 for the UK and Chinese experts respectively.

In the UK, for Level 2 criteria, all groups agree that under the Economic category, Cost is the most important criterion. Financial incentive has been weighed higher than Installation time by the architect group. Under the Environmental category, all background groups regard In-use environmental performance as more important than Recycled content. Under the Social category, the criterion of Societal benefits has been weighed higher than Organizational benefits by the architect group and the engineer group. The expert group from other backgrounds think oppositely. Under the Technical category, the architect group and the expert group from other backgrounds think Operation is more important. The results presented in Figure 8 indicate that Chinese experts have very similar opinions about relative importance of different Level 2 criteria to their UK colleagues. 


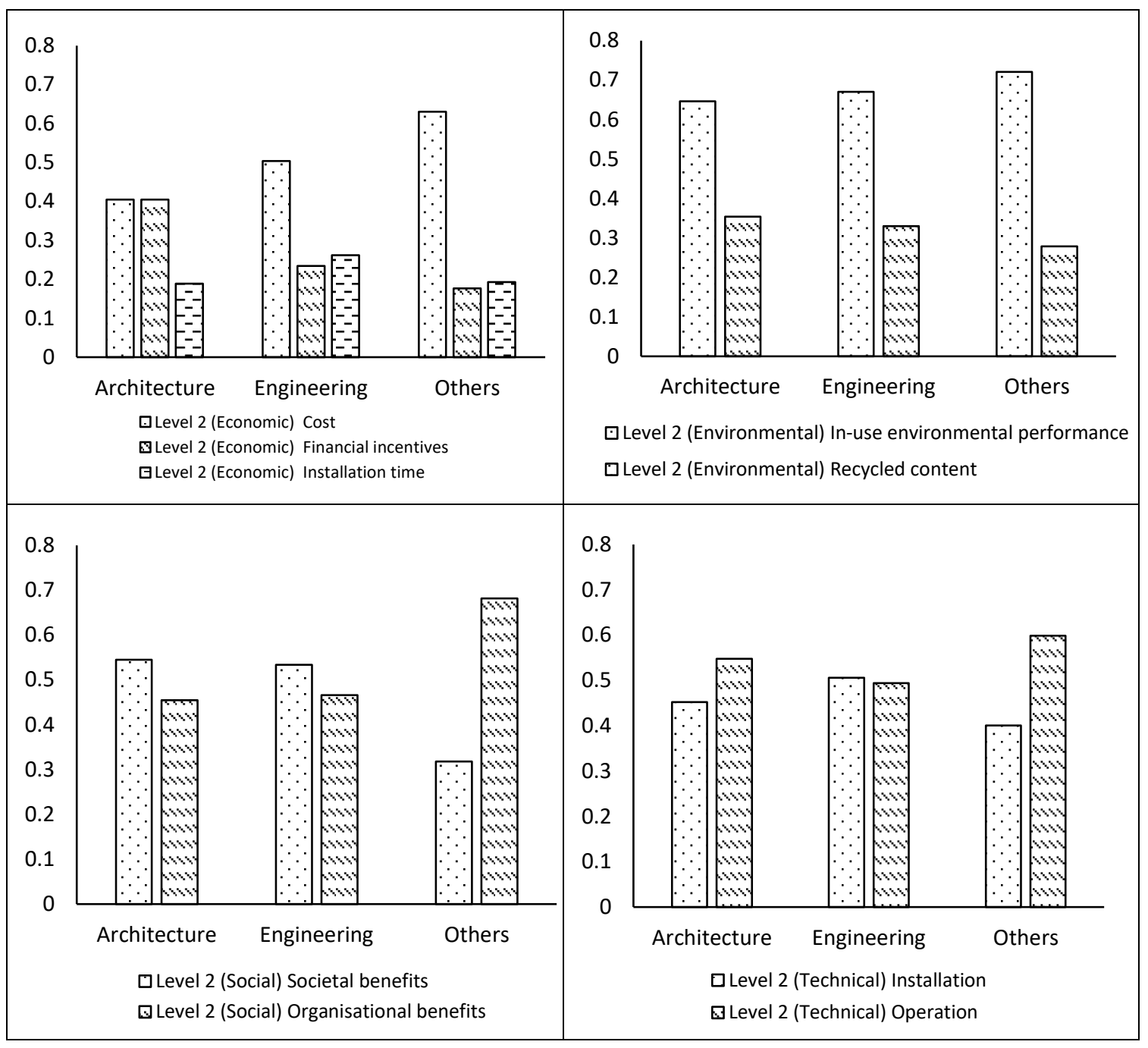

Figure 7 Comparison of Level 2 criteria by expert groups from different backgrounds in the UK

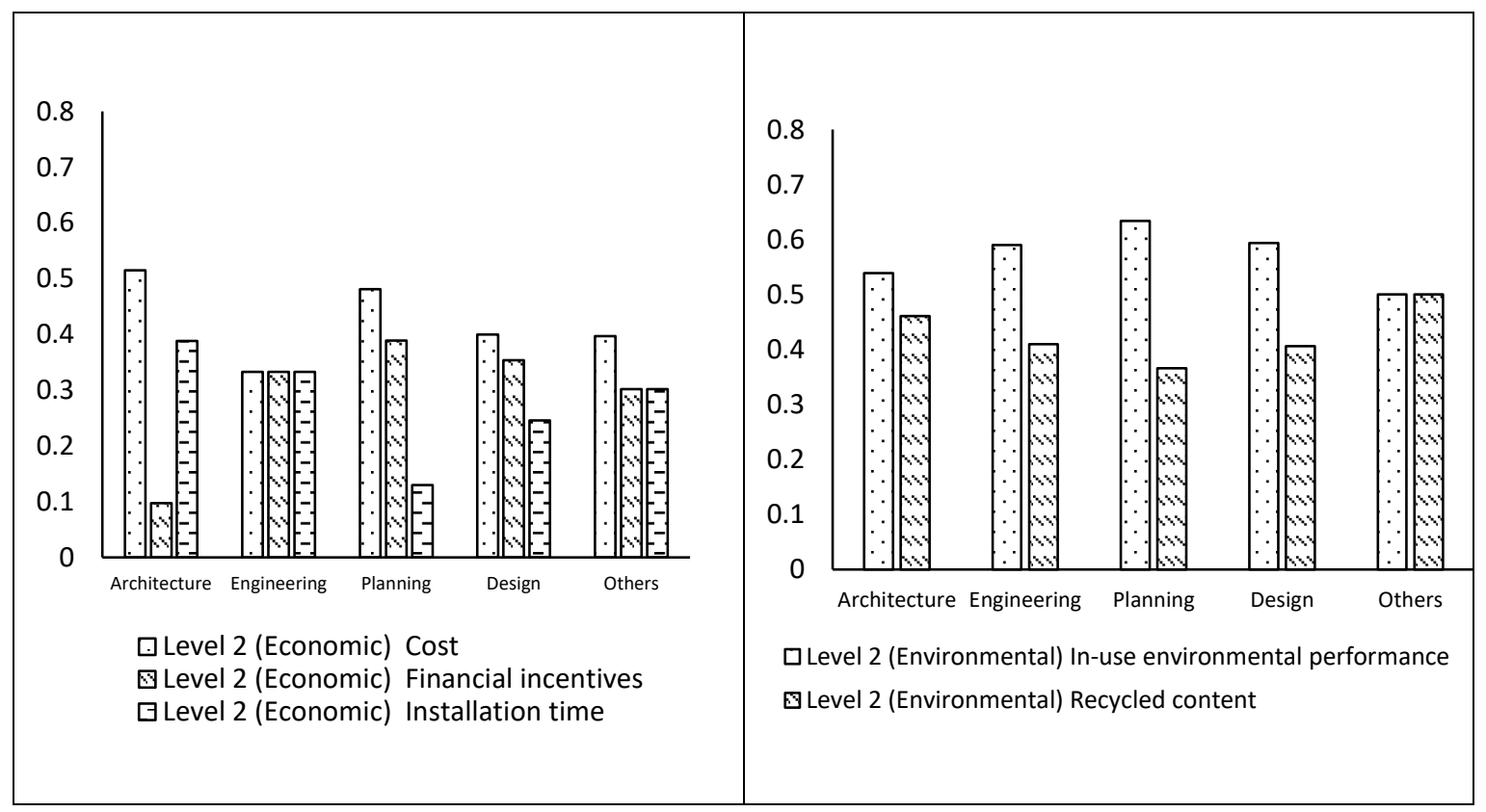




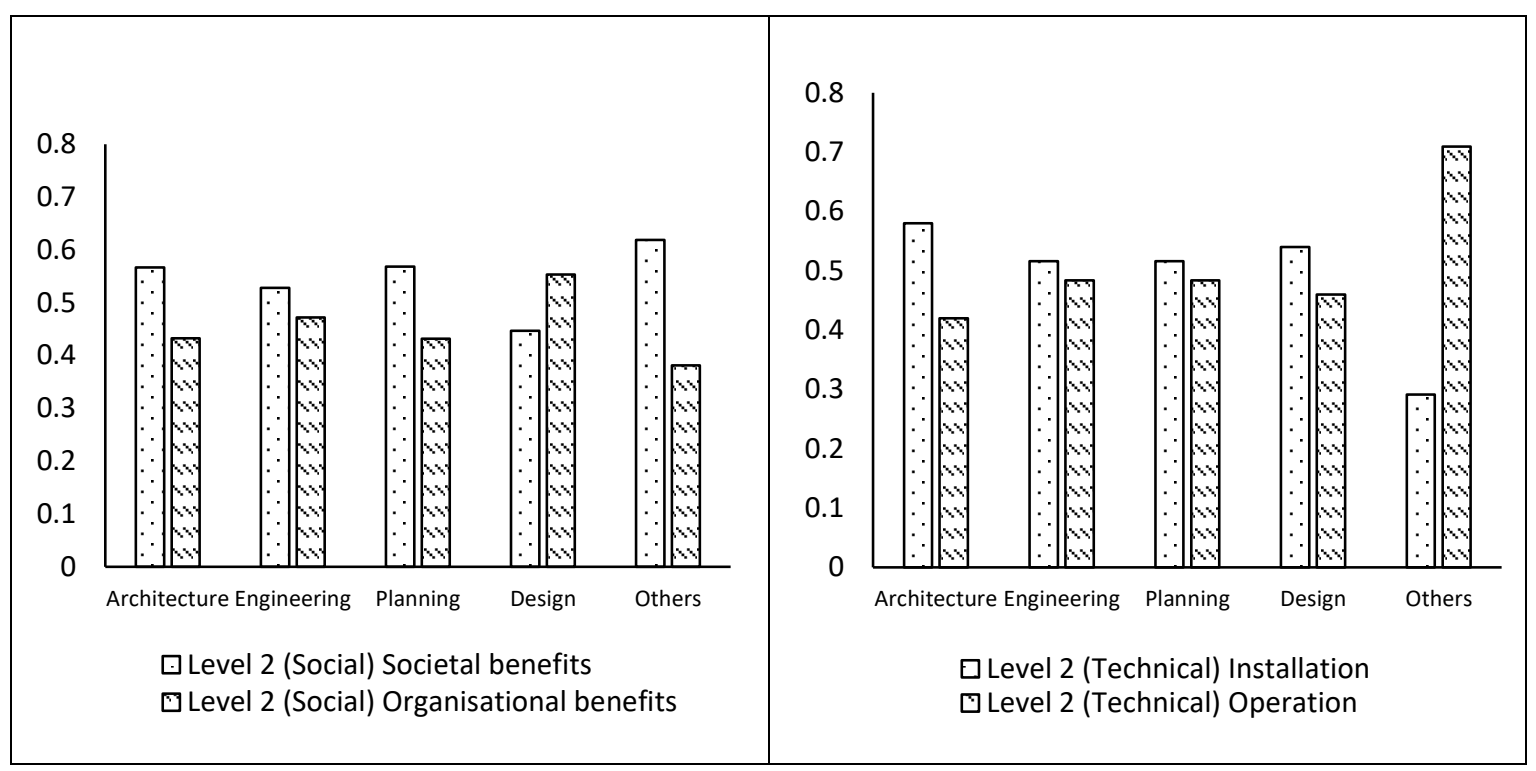

Figure 8 Comparison of Level 2 criteria by expert groups from different backgrounds in China

The default weights for Level 3 criteria in relation to a stakeholder background is presented in Figures 9 and 10 for the UK and Chinese experts respectively.

In the UK, for Level 3 criteria, under Cost, the architect group have assigned the same weights to the criteria of O\&M cost and Payback period. The engineer group have assigned equal weights to all criteria under Cost. The expert group from other backgrounds think O\&M cost should be the most important criterion under Cost. Under In-use environmental performance, the architect group think Reduction of energy consumption is the most important criterion, and the engineer group alternatively thinks Reduction of water consumption should be the most important criterion. Under Societal benefits, Job creation is much more important than Community engagement, shared by all expert groups. Under Organisational benefits, Occupant wellbeing improvement is more important than Social reputation improvement for all expert groups. Under Operation, the architect group consider Durability as the most important criterion. Other expert groups consider Reliability as the most important criterion. 


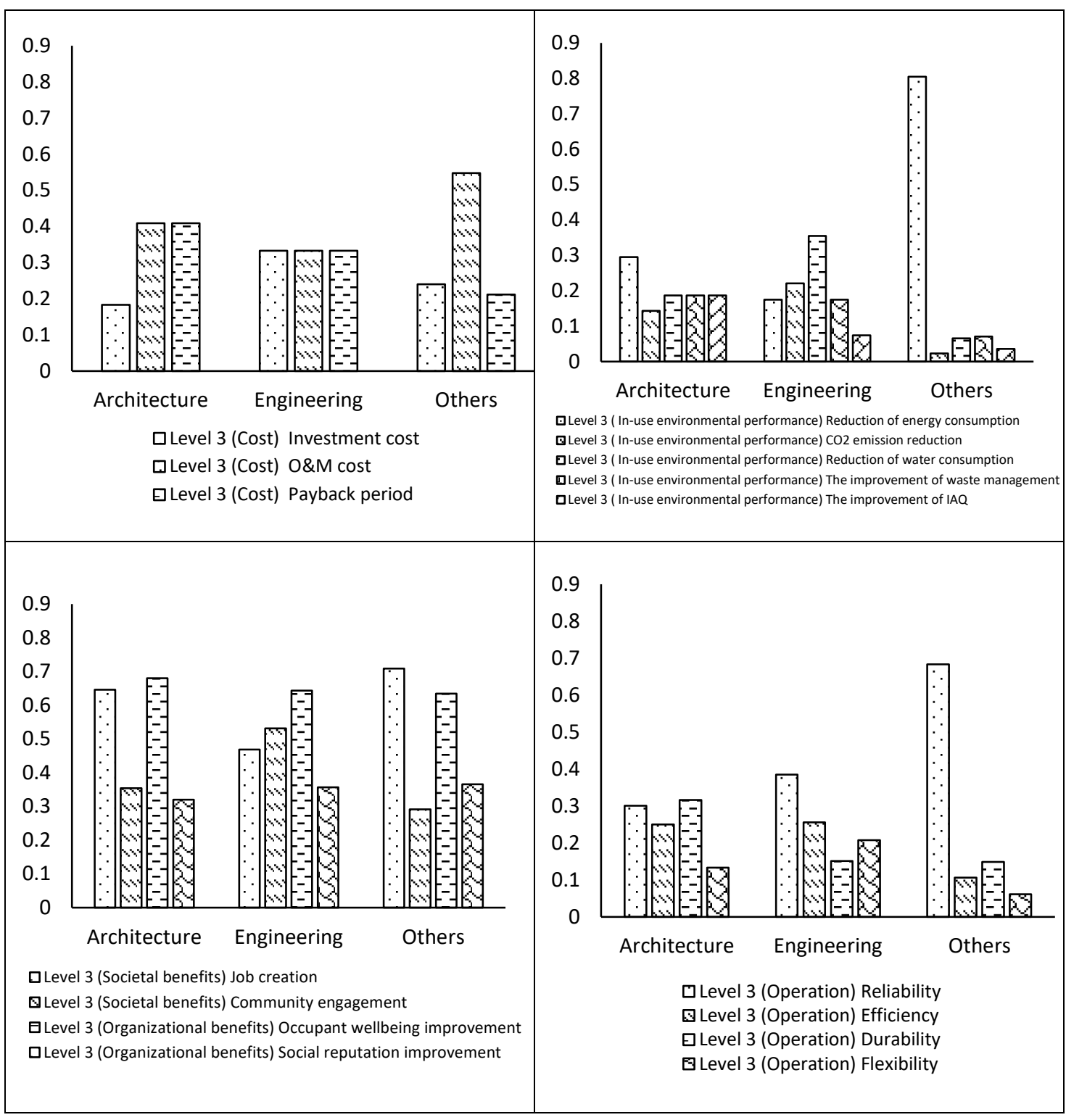

Figure 9 Comparison of Level 3 criteria by expert groups from different backgrounds in the UK

In China, for Level 3 criteria, under Cost, the architect group regards Investment cost and $O \& M$ cost as equally important. The engineer group considers $O \& M$ cost more important than Investment cost and Payback period. Other groups including the planning group, design group and experts from other backgrounds agree that Investment cost should be the most important criterion. Under In-use environmental performance, expert groups from the backgrounds of architecture and planning claim that the importance of Reduction of energy consumption override other sub-criteria. The engineer group have assigned similar weights to the criteria of Reduction of energy consumption, $\mathrm{CO}_{2}$ emission reduction and Reduction of water consumption. The expert group from other backgrounds considered Improvement of $I A Q$ as most important. For Societal benefits, all expert groups except the group from other backgrounds think Job creation is much more important than Community engagement. For Organisational benefits, all expert groups regard Occupant wellbeing improvement as more 
important than Social reputation improvement. Under Operation, different expert groups hold different opinions on the relative importance of the four sub-criteria. The architect group considers all sub-criteria equally important. The engineer group regards Durability as most important criterion. The planning group and the expert group from other backgrounds consider Reliability as most important criterion. The design group regards Flexibility as most important criterion.

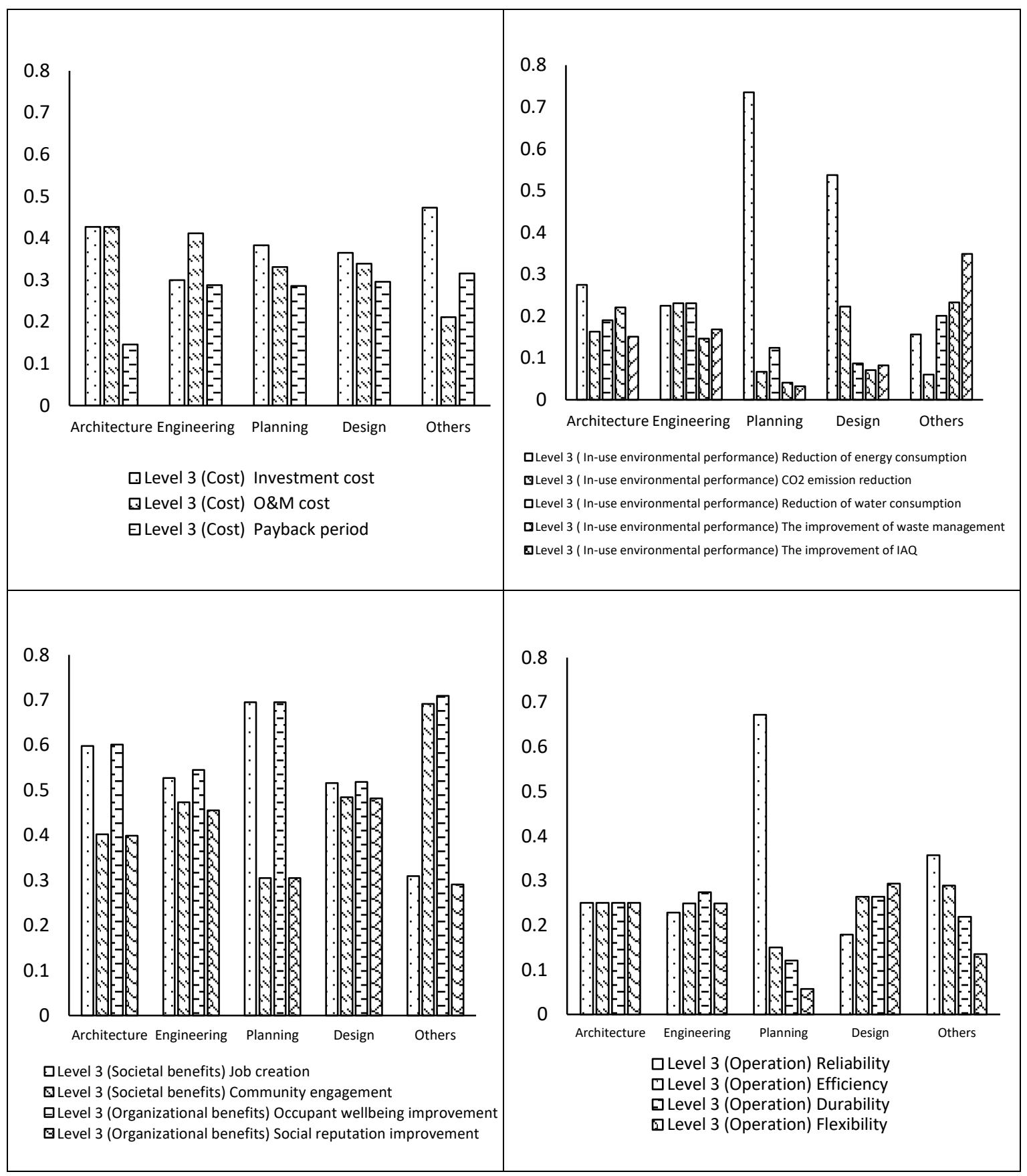

Figure 10 Comparison of Level 3 criteria by expert groups from different backgrounds in China 
The default weights for Level 4 criteria in relation to a stakeholder background is presented in Figures 11 and 12 for the UK and Chinese experts respectively.

In the UK, for Level 4 criteria, the architect group and the expert group from other backgrounds regard Material part as most important criterion. The engineer group regards Labour part as most important criterion. For the sub-criteria of the Improvement of IEQ, all the expert groups agree that the most important criterion should be Thermal comfort. The importance of Indoor air quality has been also emphasised by all expert groups. Under Occupant wellbeing improvement, all expert groups except for experts from other backgrounds consider Psychological wellbeing as more important than Productivity and performance.

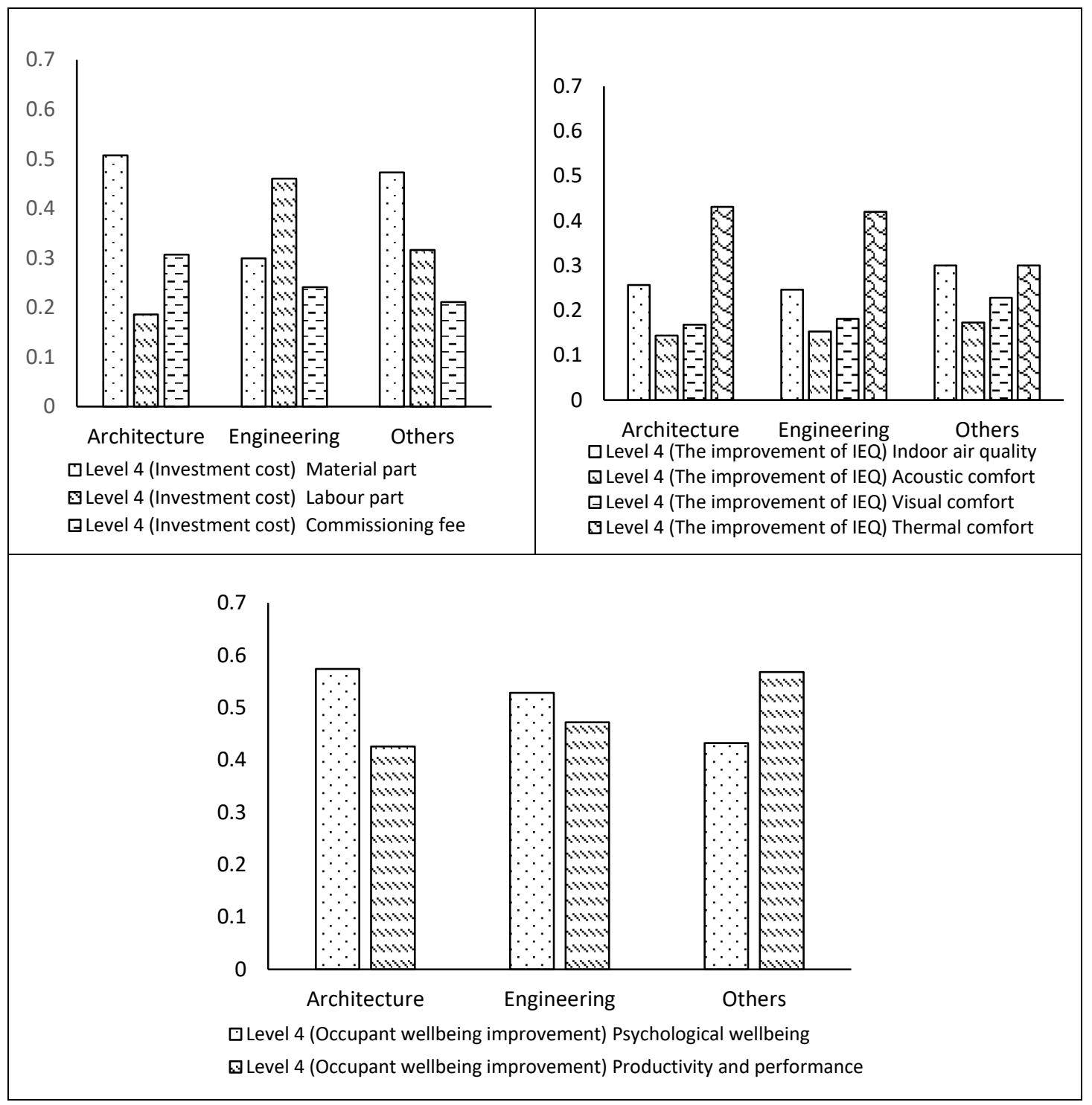

Figure 11 Comparison of Level 4 criteria by expert groups from different backgrounds in the UK 
In China, for Level 4 criteria, the architect group and planning group regard Material part as the most important criterion. Other expert groups take Labour part as the most important criterion. Under The improvement of IEQ, the architect group considers Visual comfort as most important criterion. The engineer group consider all the sub-topics with the same importance. Experts from backgrounds of planning, design and others all agree Indoor air quality is most important. Under Occupant wellbeing improvement, the majority of experts regard Psychological wellbeing improvement as more important than Productivity and performance. The expert group from other backgrounds considers them of the same importance.

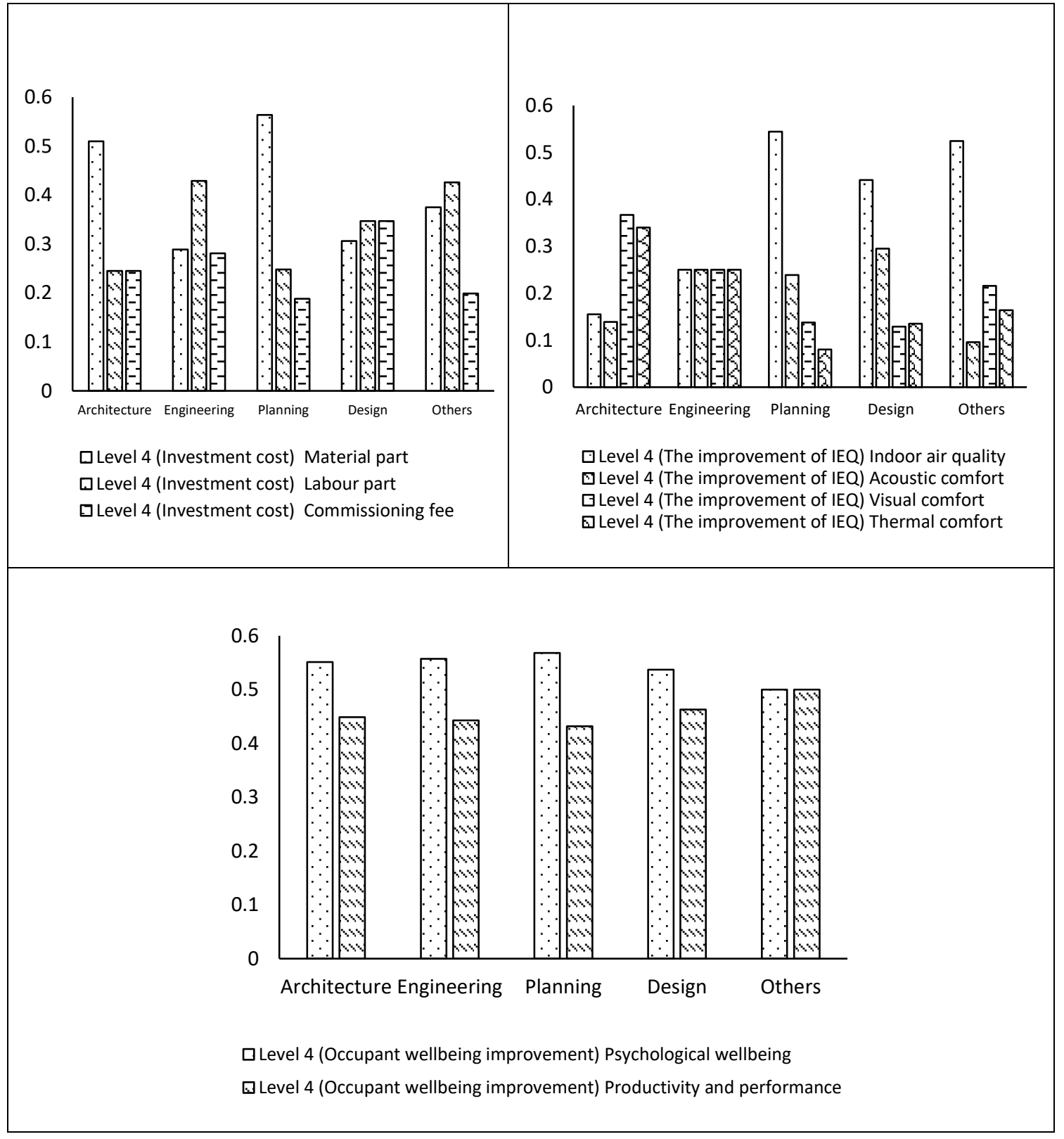

Figure 12 Comparison of Level 4 criteria by expert groups from different backgrounds in China 


\subsubsection{Criteria weighting comparison between two countries}

Criteria weighting differences are analysed between the UK and China for three different groups: all experts who responded to a survey; the architects only group and the engineers only group. The difference of criteria weights between expert groups is calculated using formula (1).

$$
\text { Weights difference }=\frac{\text { Absolute value }\left(w_{i}-w_{j}\right)}{1.000 / n} \times 100 \%
$$

Where $w_{i}$ is the criteria weight given by expert group $i, w_{j}$ is the criteria weight given by expert group $j, n$ is the dimension of pair-wise comparison matrix, $1.000 / n$ is the average criteria weights for MPC with $n$ dimensions. The exact differences are listed in Table 1 in Appendix C and are here summaried as: "Large difference" (>50\%), "Medium difference" $(20 \% \sim 50 \%)$ and "Small difference" (<20\%) [50] and presented in Figures 13 to 15.

The difference of criteria weighting by all expert groups in the UK and China (see Figure 13) can be summarised as:

1) On Level 1, UK experts appear to be more concerned with the overall Economic performance of green technologies, while Chinese experts put more emphasis on their overall Technical performance.

2) On Level 2, experts have different opinions about Financial incentives and Installation time which belong to Economic criteria. UK experts consider the availability of Financial incentives that can support technology adoption as much more important. Chinese experts, contrastively, regard Installation time as much more important.

3) On Level 3, differences are found in criteria relating to Investment Cost, In-use environmental performance and Operation. Chinese experts regard investment cost as most important criterion, while UK experts consider the other two sub-criteria, Operation and maintenance and Payback period, under Cost. Experts from UK and China have distinct opinions on the relative importance of five topics of In-use environmental performance. UK experts consider The reduction of water consumption as most important but The improvement of Indoor Environmental Quality (IEQ) is the least important, while Chinese experts consider them of similar importance. Under Operation. UK experts consider technology Reliability as highly important but Chinese experts give preference to Durability.

4) On Level 4, UK experts regard Thermal comfort as their first concern and Chinese experts regard Visual comfort as the first priority. 


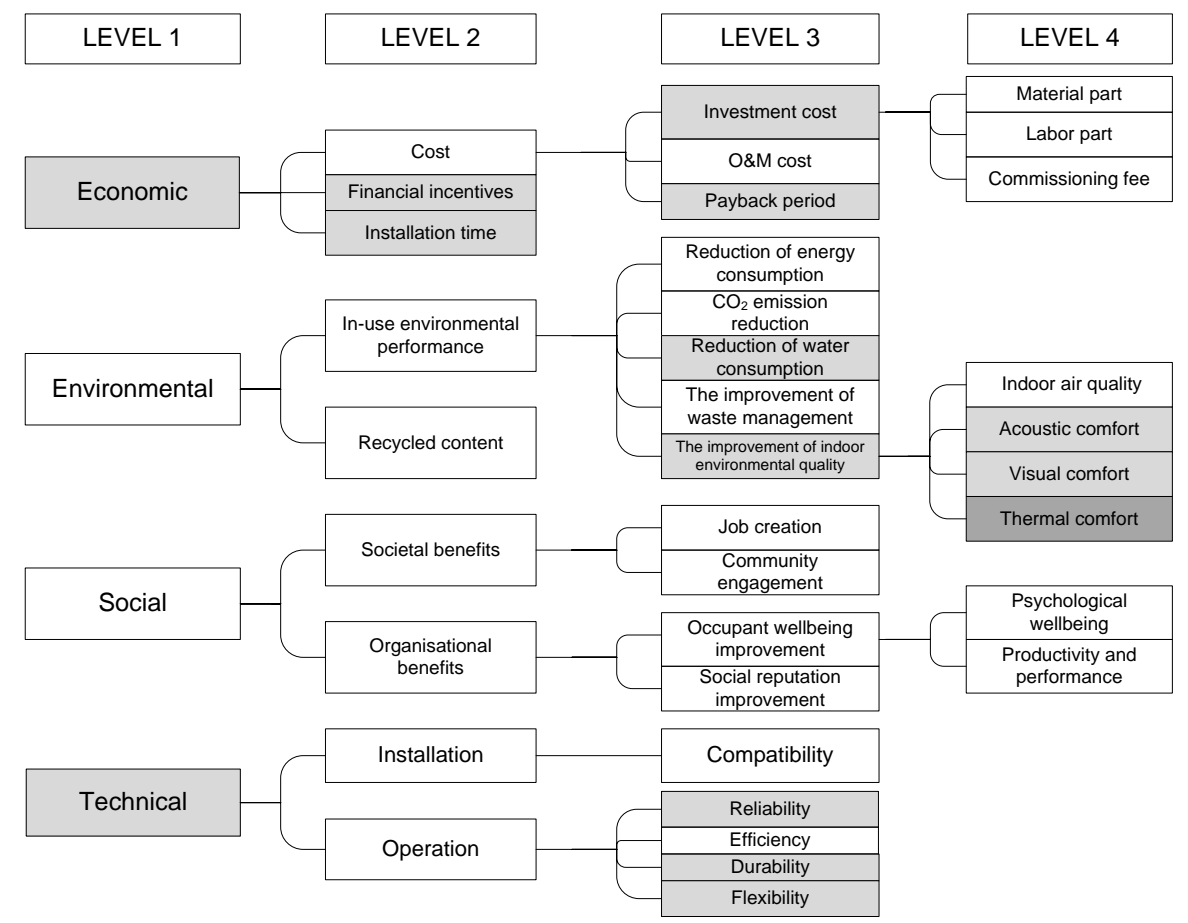

Figure 13 Difference of Criteria weighting for the all expert groups ("Large difference" (>50\%) (dark grey); "Medium difference" (20\% 50\%) (light grey); "Small difference" (<20\%) (No shading)

The difference of criteria weighting by the architect groups in the UK and China (see Figure 14) can be summarised as:

1) On Level 1, results show that architect groups from two countries have different opinions about Economic, Environmental and Social criteria. Chinese architect group consider these three criteria equally important, whilst UK architect group regard Environmental and Social criteria more important than Economic criteria.

2) On Level 2, criteria weights difference exists for all the criteria except for sub-criteria under the Social aspect. Criteria with large weighting difference are Financial incentives and Installation time. Financial incentives are weighed much higher by UK architects than Chinese architects.

3) On Level 3, large differences have been identified in the criteria of the Investment cost and the Payback period. The UK architects are more concern about Payback period while Chinese architects are more concern about Investment cost.

4) On Level 4, the differences have been identified for Indoor air quality, Visual comfort and Thermal comfort under The improvement of IEQ. Chinese architects regard Visual comfort as the most important criterion. 


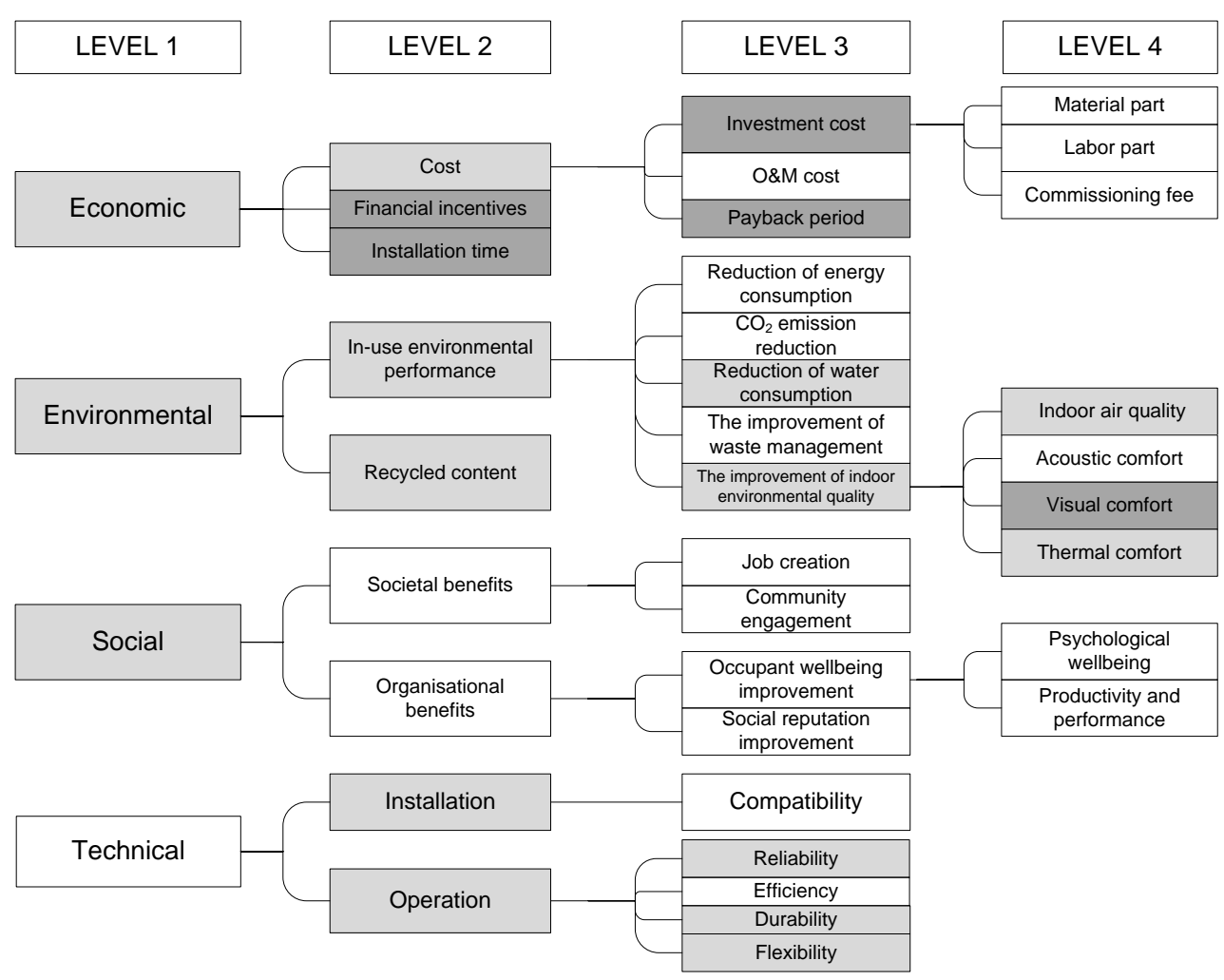

Figure 14 Difference of Criteria weighting for the architect groups ("Large difference" (>50\%) (dark grey); "Medium difference" (20\% 50\%) (light grey); "Small difference" (<20\%) (No shading))

The difference of criteria weighting by the engineer groups in the UK and China (see Figure 15) can be summarised as:

1) On Level 1, results show that engineer groups have different opinions towards Economic and Social criteria. UK engineer group are more concern about Economic criteria, whilst Chinese engineer group with Social criteria.

2) On Level 2, criteria weights differences are mainly identified for Cost, as well as Financial incentives and Installation time. The largest differences are related to Cost which is of higher concern to UK engineers than Chinese engineers.

3) On Level 3, results show that UK engineers assign more weights on The reduction of water consumption than Chinese engineers as well as technology Reliability during Operation.

4) On Level 4, UK engineer group regards Thermal comfort as their first priority. 


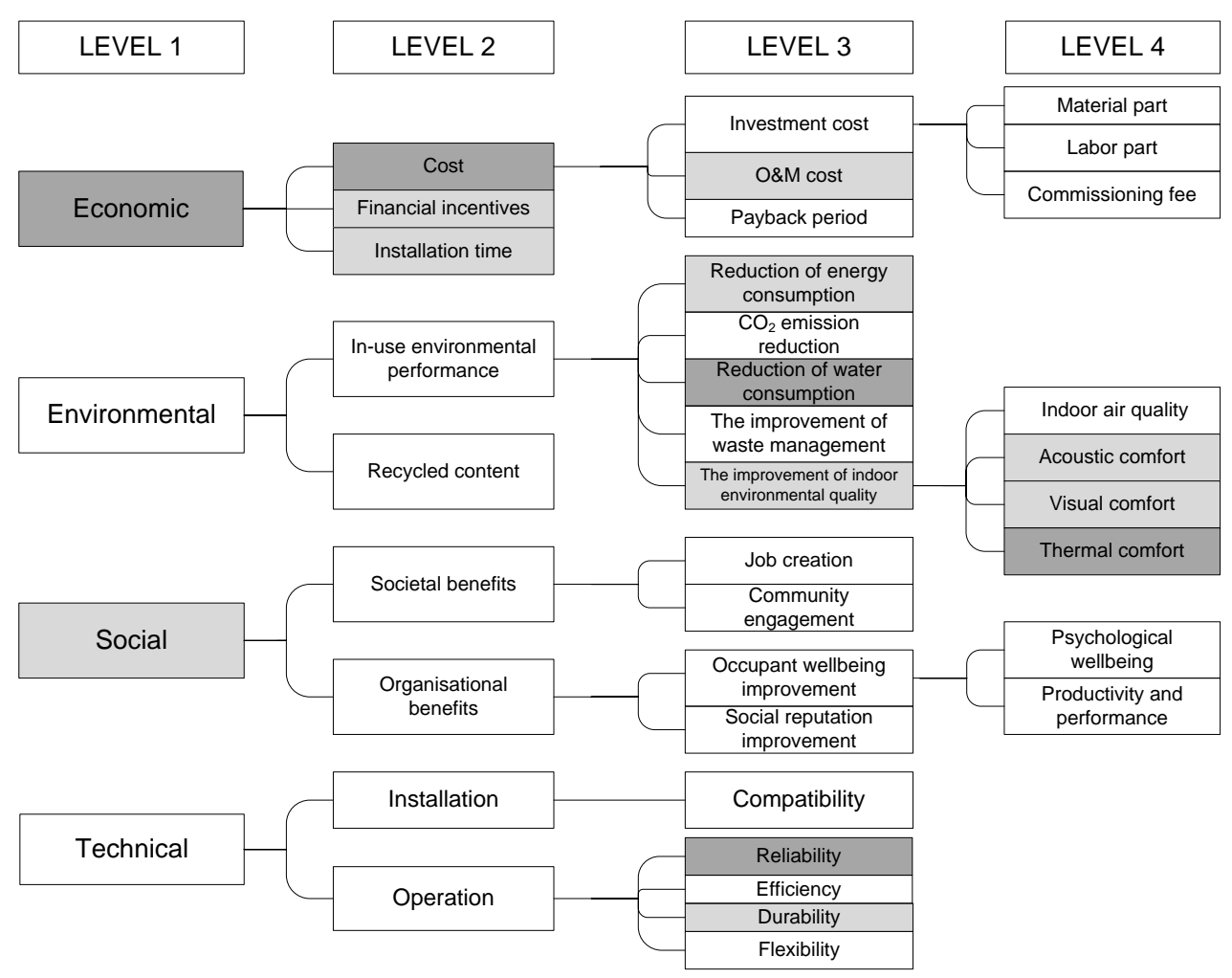

Figure 15 Difference of Criteria weighting for the engineer groups ("Large difference" ( $>50 \%$ ) (dark grey); "Medium difference" (20\% 50\%) (light grey); "Small difference" (<20\%) (No shading))

The visual summary of overall differences at national level (Figure 13) as well as summaries of differences for architect group only (Figure 14) and engineering group only(Figure 15) clearly indicates that different professional backgrounds, amount other identified 'local' factors, will influence which criteria can be seen as 'universal' and which are context dependent.

\section{Discussion}

Todd et al. [51] argues that whenever criteria are used some form of weighting is automatically applied (equal weights also assume weighing). Although this argument is used within the context of green building assessment, it applies for multiple criteria decision making process. No refurbishment criteria, and especially those involved with sustainability, can be regarded as equally relevant for every building on any location. Weighting process is however, fraught with difficulties. Given the lack of scientific objectivity, (personal) judgment will influence weighting process [51]. The existing practices used in weighting processes indicates that consensus based approach among groups of experts or stakeholders is the most common. However, seeking a consensus among specific group of experts or stakeholders involved in a specific retrofit project is not always feasible within given time and financial constraints. By proposing default criteria weights for previously developed criteria tree, opportunities for adopting the method of integrative assessment for green technology selection are maximised. The authors are fully aware that the proposed retrofit criteria and default weighting factors present just one way of approaching the problem. However, used 
together, criteria and weighting factors, offer the opportunity to all parties involved to investigate different retrofit options for non-domestic buildings.

Criteria weights comparison between expert groups in UK and China can further indicate criteria preferences of expert groups when involved in selecting the optimal technology for non-domestic building retrofits. For four general aspects of Economic, Environmental, Social and Technical performance of possible green technologies UK experts place more emphasis on Economic criteria, more specifically sub-criteria of Cost and Financial incentives for green technology. UK architects have especially placed higher weights on Financial incentives. Chinese experts, in contrast, are more concerned about Technical criteria. This difference between UK and China is supported by the results of most-frequent client requirements. In the UK, they are "to reduce operational cost" and "to increase asset value". Comparatively, in China, the most frequent client requirement is found to be "to improve building safety and security. For In-use environmental performance, Reduction of energy consumption and Reduction of water consumption are ranked as two most important topics in both countries. UK experts, especially engineer group, tend to put more emphasis on water efficiency over energy efficiency. Under Indoor environmental quality, Thermal comfort is regarded by UK experts as their first priority, whilst Chinese experts regard Visual comfort as their first priority, especially by architect group. It has been found there is no obvious difference from all expert groups on Social criteria weighting, but Chinese engineer group have paid a particular emphasis on Social criteria. Chinese experts give more emphasise on Technical criteria, eg. Durability compared to their UK colleagues.

The weighting factors were developed based on collected responses from relevant professionals with experience in retrofit projects at two locations: UK and China. The comparison of criteria weights between both national groups as well as based on professional background is performed and presented. Whilst the findings do not claim to be statistically representative, they do give an insight into relative importance of proposed economic, environmental, social and technical criteria depending on professional background as well as national context. UK and China are at different stages of economical development, their non-domestic building stock have different characteristics and have different professional as well as regulative practices. Whether or not similar difference in relative importance of proposed refurbishment criteria would be found in countries with similar non-domestic building stock, professional, legislative and economical characteristics is not certain and needs further research. This study of criteria weighting is developed to provide opportunities for integrative assessment method involving multiple criteria when selecting green technologies as part of non-domestic building retrofit process. In the absence of project specific criteria weights, previously proposed criteria tree and now proposed default criteria weights can enable an informed decision making process and further the understanding how different professional backgrounds in specific national context (UK and China) can influence this decision making process.

Our research has contributed, at least to some extent, to the understanding of stakeholder perspectives and country contexts' influence on criteria weighting. As criteria weights can directly influence the ranking order of alternatives and the final results, the selection which takes into account stakeholder perspectives and country development is 
essential. Based on the proposed multiple criteria tree, criteria weights were collected from industry professionals through the surveys for UK and China. Our results can present an unique insight into how different professional backgrounds affect individual value positions in relation to proposed retrofit criteria. UK and China became examples of certain national contexts (professional and legislative practises, building stock characteristics) for us to extend the arguments relating to how weighting systems in general are designed and created.

However, the major method in this research, AHP method, has its intrinsic limitations. A portion of the survey responses using the AHP method was checked inconsistent, with consistency ratios $>0.1$. However, this inconsistency seems not to be unusual in making paired comparisons, just as in thinking, people do not have the intrinsic logical ability to always be consistent. Existing research has shown that the use of AHP requires substantial beforehand training and the usage could be explained in semi-interviews or workshops, where consistent judgements from participants are much easier to manage.

The AHP method can also be implemented through the Expert Choice, a software professionally designed for the method, a reminder of inconsistency will be triggered for users and more consistent results can be received. By identifying the limitations of the research design and the AHP method, future works could be conducted in the way that the survey of criteria weighting is designed with the assistance of the Expert Choice. With more consistent results achieved through the software, a validation of criteria weights could be further carried out. In the validation process, the Pearson correlation test can be conducted between the weights elicited through the Expert Choice software and the weights proposed through the web-based surveys, and the correlation coefficient between these two results can be calculated. Criteria weights with the low correlation coefficient will be identified and validated in the future research. 


\section{References}

[1] P. Newton and X.M. Bai (2008). Transitioning to Sustainable Urban Development. In: Transitions: Pathways Towards Sustainable Urban Development in Australia. P. Newton Ed. CSIRO Publishing and Springer, 3-19.

[2] UNEP (2015). Annual Report 2015. Available at:

http://web.unep.org/annualreport/2015/en/index.html

[3] S. Wilkinson (2012). Analysing sustainable retrofit potential in premium office buildings. Structural Survey, 30(5), 398-410.

[4] D. Clements-Croome. ed. (2006). Creating the productive workplace. Taylor \& Francis. [5] P.O.Akadiri, E.A. Chinyio and P.O. Olomolaiye (2012). Design of a sustainable building: A conceptual framework for implementing sustainability in the building sector. Buildings, 2(2), 126-152.

[6] BRE, BREEAM in-use international. Technical manual, Available at: https://tools.breeam.com/filelibrary/Technical\%20Manuals/SD221 BIU International 201 5 Re-issue V2.0.pdf, 2016.

[7] Y. K. Juan, P. Gao and J. Wang (2010). A hybrid decision support system for sustain-able office building renovation and energy performance improvement. Energy and Buildings, 42(3), 290-297.

[8] S.E. Chidiac, E.J.C. Catania, E. Morofsky and S. Foo (2011). Effectiveness of single and multiple energy retrofit measures on the energy consumption of office buildings. Energy, 36(8), 5037-5052.

[9] C.C. Menassa (2011). Evaluating sustainable retrofits in existing buildings under uncertainty. Energy and Buildings, 43(12), 3576-3583.

[10] BRE, Morelands Rooftop, London, Available at: http://www.breeam.com/index.jsp?id=798, 2015a.

[11] BRE, Washington Plaza, Paris, Available at: http://www.breeam.com/index.jsp?id=799, 2015b.

[12] C. Langston, F.K. Wong, E.C. Hui and L.Y. Shen (2008). Strategic assessment of building adaptive reuse opportunities in Hong Kong. Building and Environment, 43(10), 1709-1718.

[13] H.F. Castleton, V. Stovin, S.B. Beck and J.B. Davison (2010). Green roofs; building energy savings and the potential for retrofit. Energy and buildings, 42(10), 1582-1591.

[14] Z. Ma, P. Cooper, D. Daly and L. Ledo (2012). Existing building retrofits: Methodology and state-of-the-art. Energy and Buildings, 55, 889-902

[15] R. Ruparathna, K. Hewage and R. Sadiq (2016). Improving the energy efficiency of the existing building stock: A critical review of commercial and institutional buildings. Renewable and Sustainable Energy Reviews, 53, 1032-1045.

[16] M.M. Rahman, M.G. Rasul and M.M.K. Khan (2010). Energy conservation measures in an institutional building in sub-tropical climate in Australia. Applied Energy, 87(10), 2994-3004.

[17] Y. Huang, J.L. Niu, and T.M. Chung (2013). Study on performance of energy-efficient retrofitting measures on commercial building external walls in cooling-dominant cities. Applied Energy.103, 97-108 
[18]J.J. Wang, Y.Y. Jing and C.F. Zhang (2009). Weighting methodologies in multi-criteria evaluations of combined heat and power systems. International journal of energy research. 33,1023-1039.

[19] W. Pan, A.R. Dainty and A.G. Gibb (2012). Establishing and weighting decision criteria for building system selection in housing construction. Journal of Construction Engineering and Management, 138(11), 1239-1250.

[20] Z. Dangana, W. Pan and S. Goodhew (2013). A decision making system for selecting sustainable technologies for retail buildings. Energy and the Built Environment Proceedings.

[21] L. Bourdeau (1999). Sustinable development and the future of construction: a comparison of visions from various contries. Building Research and Information, 27(6), 354-366

[22] CIB (1999). Agenda 21 on Sustainable Construction. CIB Report.

[23] S. Zainab, W. Pan, S. Goodhew and A. Fuertes (2013). Stakeholders perspective on sustainable technology selection to achieve zero carbon retail buildings. Management, 1219-1229.

[24] Z.A. Collier, D. Wang, J.T. Vogel, E.K. Tatham and I. Linkov (2013). Sustainable roofing technology under multiple constraints: a decision-analytical approach. Environment Systems and Decisions, 33(2), 261-271.

[25] C. Macharis, L. Turcksin and K. Lebeau (2012). Multi actor multi criteria analysis (MAMCA) as a tool to support sustainable decisions: State of use. Decision Support Systems, 54(1), 610-620.

[26] J.Si, L. Marjanovic-Halburd, F. Nasiri and S. Bell (2016). Assessment of building-integrated green technologies: A review and case study on applications of Multi-Criteria Decision Making (MCDM) method. Sustainable Cities and Society, 27,106-115.

[27] M. Pöyhönen and R.P. Hämäläinen (1998). On attribute weighting in value trees. Helsinki University of Technology, Systems Analysis Laboratory.

[28] E. Løken (2007). Use of multi-criteria decision analysis methods of energy planning problems. Renewable and Sustainable Energy reviews. 11,1584-1595.

[29] V. Ibáñez-Forés, M.D. Bovea, and V. Pérez-Belis (2014). A holistic review of applied methodologies for assessing and selecting the optimal technological alternative from a sustainability perspective. Journal of Cleaner Production, 70, 259-281.

[30] N.H. Zardari, K. Ahmed, S.M. Shirazi, and Z.B. Yusop (2015) Weighting Methods and their effects on Multi-Criteria Decision Making Model Outcomes in Water Resources Management. USA: Springer Press

[31] I. Linkov and E. Moberg (2012). Multi-criteria Decision Analysis: Environmental Applications And Case Studies. USA: CRC Press.

[32] T.L.Saaty (1990). How to make a decision: The analytic hierarchy process. European Journal of Operational Research. 48(1) , 9-26.

[33] T.L. Saaty (1989). Group decision making and AHP, in: B. Golden, E. Wasil, P. Harker (Eds.), The Analytic Hierarchy Process: Applications and Studies, Springer-Verlag, New York. 
[34] R.F. Dyer and E.H. Forman (1992). Group decision support with the analytic hierarchy process. Decision support systems, 8(2), 99-124.

[35] Y. Chen, G.E. Okudan and D.R. Riley (2010). Sustainable performance criteria for construction method selection in concrete buildings. Automation in construction, 19(2), 235-244.

[36] C.C. Menassa and B. Baer (2014). A framework to assess the role of stakeholders in sustainable building retrofit decisions. Sustainable Cities and Society, 10, 207-221.

[37] C. Banville, M. Landry, J.M. Martel and C. Boulaire (1998). A stakeholder approach to MCDA. Systems Research and Behavioral Science, 15(1), 15-32.

[38] E. Rey (2004). Office building retrofitting strategies: multi-criteria approach of an architectural and technical issue. Energy and Buildings. 36(4), 367-372.

[39] H.M. Bernstein and M.A. Russo (2009). Green building retrofit and renovation: Rapidly expanding market opportunities through existing buildings. Smart Market Report. McGraw Hill Construction.

[40] J. Yudelson (2010). Greening existing buildings. New York: McGraw-Hill.

[41] B. Huang, H. Yang, V. Mauerhofer and R. Guo (2012). Sustainability assessment of low carbon technologies-case study of the building sector in China. Journal of Cleaner Production, 32, 244-250.

[42] J. A. Todd and S. Geissler (1999).R. Regional and cultural issues in environmental performa nce assessment for buildings. Building Research and Information, 27(4-5), 247-256

[43] R. Raslan (2010). Performance Based Regulations: The Viability of the Modelling Approach as a Methodology for Building Energy Compliance Demonstration. PhD. University College London.

[44] E. K. Foreman (1991). Survey sampling principles. USA, New York.

[45] P. Ardilly and Y. Tillé (2006). Sampling methods: Exercises and solutions. Springer Science \& Business Media.

[46] J. Si (2017). Green retrofit of existing non-domestic buildings as a multi criteria decision making process. PhD. University College London.

[47] P. Konidari and D. Mavrakis (2007). A multi-criteria evaluation method for climate change mitigation policy instruments. Energy Policy, 35(12),6235-6257.

[48] J. Aczel and T.L. Saaty (1983). Procedures for synthesizing ratio judgements, Journal of Mathematical Psychology 27, 93-102.

[49] J. Ritchie, J. Lewis, C. McNaughton-Nicholls and R. Ormston. (2014). Qualitative Research Practice: A guide for Socila Scinecne Students and Researchers, SAGE.

[50] C.C. Menassa and B. Baer (2014) A framework to assess the role of stakeholders in sustainable building retrofit decisions. Sustainable Cities and Society. 10: 207-221.

[51] J.A. Todd, D. Crawley, S. Geissler and G. Lidnsey. (2001). Comperative assessment of environmental performance tools and the role of the Green Building Challenge. Building Research and Information, 29(5), 324-335 


\section{Appendix A}

Table A.1 Numbers of matrices that have passed consistency checking

\begin{tabular}{|c|c|c|c|c|c|c|c|}
\hline \multirow[b]{2}{*}{ Level } & \multirow[b]{2}{*}{ Dimensions } & \multicolumn{3}{|c|}{ UK } & \multicolumn{3}{|c|}{ China } \\
\hline & & $\begin{array}{l}\text { All Expert } \\
\text { group }\end{array}$ & $\begin{array}{l}\text { Architect } \\
\text { group }\end{array}$ & $\begin{array}{l}\text { Engineer } \\
\text { group }\end{array}$ & $\begin{array}{l}\text { All expert } \\
\text { group }\end{array}$ & $\begin{array}{c}\text { Architect } \\
\text { group }\end{array}$ & $\begin{array}{c}\text { Engineer } \\
\text { group }\end{array}$ \\
\hline Level 1 & $4 \times 4$ & 14 & 4 & 9 & 4 & 1 & 2 \\
\hline $\begin{array}{c}\text { Level } 2 \\
\text { (Economic) }\end{array}$ & $3 \times 3$ & 9 & 4 & 5 & 7 & 1 & 2 \\
\hline Level 3 (Cost) & $3 \times 3$ & 4 & 2 & 2 & 9 & 3 & 4 \\
\hline $\begin{array}{l}\text { Level } 3 \text { (In-use } \\
\text { Environmental } \\
\text { Performance) }\end{array}$ & $5 \times 5$ & 2 & 1 & 1 & 9 & 3 & 4 \\
\hline $\begin{array}{c}\text { Level } 3 \\
\text { (Operation) }\end{array}$ & $4 \times 4$ & 11 & 4 & 7 & 6 & 2 & 3 \\
\hline $\begin{array}{c}\text { Level } 4 \\
\text { (Investment cost) }\end{array}$ & $3 \times 3$ & 9 & 4 & 4 & 10 & 3 & 6 \\
\hline $\begin{array}{c}\text { Level } 4 \\
\text { (The improvement } \\
\text { of IEQ) }\end{array}$ & $4 \times 4$ & 16 & 4 & 10 & 8 & 3 & 2 \\
\hline
\end{tabular}

Note: In Table A.1, the dimensions of MPC means that the dimension of the matrix which is formed by pair-wise comparisons of the criteria on each level. For example, on Level 1 , there are four criteria, and the dimension of the matrix is $4 \times 4$.

Table A.2 Consistency ratios of matrices for Group Weighting Values generation

\begin{tabular}{ccccccc}
\hline & \multicolumn{3}{c}{ UK } & & \multicolumn{2}{c}{ China } \\
\cline { 2 - 7 } Level & $\begin{array}{c}\text { All Expert } \\
\text { group }\end{array}$ & $\begin{array}{c}\text { Architect } \\
\text { group }\end{array}$ & $\begin{array}{c}\text { Engineers } \\
\text { group }\end{array}$ & $\begin{array}{c}\text { All Expert } \\
\text { group }\end{array}$ & $\begin{array}{c}\text { Architect } \\
\text { group }\end{array}$ & $\begin{array}{c}\text { Engineer } \\
\text { group }\end{array}$ \\
\hline Level 1 & 0.002 & 0.004 & 0.002 & 0.012 & 0.000 & 0.013 \\
\hline Level 2 (Economic) & 0.000 & 0.000 & 0.000 & 0.000 & 0.040 & 0.000 \\
\hline Level 3 (Cost) & 0.000 & 0.000 & 0.000 & 0.002 & 0.000 & 0.001 \\
\hline $\begin{array}{c}\text { Level 3 (In-use } \\
\text { Environmental }\end{array}$ & 0.042 & 0.084 & 0.049 & 0.004 & 0.000 & 0.002 \\
\hline $\begin{array}{c}\text { Lerformance) } \\
\text { Level 3 (Operation) }\end{array}$ & 0.009 & 0.004 & 0.014 & 0.001 & 0.000 & 0.000 \\
\hline $\begin{array}{c}\text { Level 4 } \\
\text { Investment cost) }\end{array}$ & 0.000 & 0.001 & 0.000 & 0.000 & 0.002 & 0.000 \\
\hline $\begin{array}{c}\text { Level 4 (The } \\
\text { improvement of IEQ) }\end{array}$ & 0.004 & 0.009 & 0.003 & 0.002 & 0.000 \\
\hline
\end{tabular}




\section{Appendix B}

Table B.1 The default criteria weights assigned by different expert groups from UK and China

\begin{tabular}{|c|c|c|c|c|c|c|c|}
\hline \multirow{2}{*}{ Criteria } & \multirow{2}{*}{ Sub-criteria } & UK & China & UK & China & UK & China \\
\hline & & All & All & Architects & Architects & Engineers & Engineers \\
\hline \multirow{4}{*}{ Level 1} & Economic & 0.296 & 0.190 & 0.173 & $0.250^{\star}$ & 0.326 & 0.189 \\
\hline & Environmental & 0.279 & 0.290 & 0.303 & $0.250^{*}$ & 0.289 & 0.282 \\
\hline & Social & 0.185 & 0.181 & 0.303 & $0.250^{\star}$ & 0.152 & 0.248 \\
\hline & Technical & 0.240 & 0.338 & 0.220 & $0.250^{\star}$ & 0.234 & 0.282 \\
\hline \multirow{3}{*}{ Level 2 (Economic) } & Cost & 0.465 & 0.467 & 0.405 & $0.515^{\star}$ & 0.504 & 0.333 \\
\hline & Financial incentives & 0.304 & 0.226 & 0.405 & $0.097^{\star}$ & 0.234 & 0.333 \\
\hline & Installation time & 0.231 & 0.306 & 0.189 & $0.388^{\star}$ & 0.262 & 0.333 \\
\hline \multirow{2}{*}{ Level 2 (Environmental) } & In-use environmental performance & 0.665 & 0.577 & 0.646 & 0.539 & 0.670 & 0.590 \\
\hline & Recycled content & 0.335 & 0.423 & 0.354 & 0.461 & 0.330 & 0.410 \\
\hline \multirow{2}{*}{ Level 2 (Social) } & Societal benefits & 0.521 & 0.543 & 0.545 & 0.567 & 0.534 & 0.528 \\
\hline & Organisational benefits & 0.479 & 0.457 & 0.455 & 0.433 & 0.466 & 0.472 \\
\hline \multirow{2}{*}{ Level 2 (Technical) } & Installation & 0.475 & 0.525 & 0.452 & 0.580 & 0.506 & 0.516 \\
\hline & Operation & 0.525 & 0.475 & 0.548 & 0.420 & 0.494 & 0.484 \\
\hline \multirow{3}{*}{ Level 3 (Cost) } & Investment cost & 0.251 & 0.342 & 0.183 & 0.427 & 0.333 & 0.300 \\
\hline & O\&M cost & 0.375 & 0.433 & 0.409 & 0.427 & 0.333 & 0.412 \\
\hline & Payback period & 0.375 & 0.225 & 0.409 & 0.146 & 0.333 & 0.288 \\
\hline \multirow{3}{*}{$\begin{array}{c}\text { Level } 3 \text { (In-use environmental } \\
\text { performance) }\end{array}$} & Reduction of energy consumption & 0.233 & 0.245 & $0.295^{\star}$ & 0.275 & $0.175^{*}$ & 0.225 \\
\hline & $\mathrm{CO}_{2}$ emission reduction & 0.186 & 0.161 & $0.143^{*}$ & 0.163 & $0.221^{*}$ & 0.231 \\
\hline & Reduction of water consumption & 0.271 & 0.211 & $0.187^{\star}$ & 0.190 & $0.355^{\star}$ & 0.231 \\
\hline
\end{tabular}




\begin{tabular}{|c|c|c|c|c|c|c|c|}
\hline & The improvement of waste management & 0.189 & 0.187 & $0.187^{*}$ & 0.221 & $0.175^{*}$ & 0.146 \\
\hline & The improvement of IEQ & 0.122 & 0.196 & $0.187^{\star}$ & 0.151 & $0.074^{*}$ & 0.168 \\
\hline \multirow{2}{*}{ Level 3 (Societal benefits) } & Job creation & 0.561 & 0.536 & 0.646 & 0.598 & 0.469 & 0.527 \\
\hline & Community engagement & 0.439 & 0.464 & 0.354 & 0.402 & 0.531 & 0.473 \\
\hline \multirow{2}{*}{ Level 3 (Organizational benefits) } & Occupant wellbeing improvement & 0.657 & 0.574 & 0.680 & 0.601 & 0.643 & 0.545 \\
\hline & Social reputation improvement & 0.343 & 0.426 & 0.320 & 0.399 & 0.357 & 0.455 \\
\hline \multirow{4}{*}{ Level 3 (Operation) } & Reliability & 0.359 & 0.239 & 0.301 & 0.250 & 0.385 & 0.228 \\
\hline & Efficiency & 0.259 & 0.25 & 0.250 & 0.250 & 0.256 & 0.249 \\
\hline & Durability & 0.202 & 0.262 & 0.316 & 0.250 & 0.151 & 0.274 \\
\hline & Flexibility & 0.180 & 0.250 & 0.133 & 0.250 & 0.208 & 0.249 \\
\hline \multirow{3}{*}{ Level 4 (Investment cost) } & Material part & 0.400 & 0.332 & 0.507 & 0.510 & 0.299 & 0.289 \\
\hline & Labour part & 0.310 & 0.376 & 0.186 & 0.245 & 0.460 & 0.429 \\
\hline & Commissioning fee & 0.290 & 0.292 & 0.307 & 0.245 & 0.241 & 0.281 \\
\hline \multirow{4}{*}{ Level 4 (The improvement of IEQ) } & Indoor air quality & 0.248 & 0.206 & 0.257 & 0.155 & 0.246 & 0.250 \\
\hline & Acoustic comfort & 0.152 & 0.211 & 0.144 & 0.139 & 0.153 & 0.250 \\
\hline & Visual comfort & 0.184 & 0.305 & 0.168 & 0.367 & 0.181 & 0.250 \\
\hline & Thermal comfort & 0.416 & 0.278 & 0.431 & 0.340 & 0.420 & 0.250 \\
\hline \multirow{2}{*}{$\begin{array}{c}\text { Level } 4 \text { (Occupant wellbeing } \\
\text { improvement) }\end{array}$} & Psychological wellbeing & 0.538 & 0.543 & 0.574 & 0.551 & 0.528 & 0.557 \\
\hline & Productivity and performance & 0.462 & 0.457 & 0.426 & 0.449 & 0.472 & 0.443 \\
\hline
\end{tabular}




\section{Appendix C}

Table C.1 Categorisation of criteria weights difference by expert groups in the UK and China

\begin{tabular}{|c|c|c|c|c|c|c|c|}
\hline \multirow{2}{*}{ Criteria } & \multirow{2}{*}{ Sub-criteria } & \multicolumn{3}{|c|}{ Criteria weights difference (\%) } & \multicolumn{3}{|c|}{ Criteria weights difference (In Levels) } \\
\hline & & All expert & Architect group & Engineer group & All expert & Architect group & Engineer group \\
\hline \multirow{4}{*}{ Level 1} & Economic & 42.40 & 30.80 & 54.80 & Medium & Medium & Large \\
\hline & Environmental & 4.40 & 21.20 & 2.80 & Small & Medium & Small \\
\hline & Social & 1.60 & 21.20 & 38.40 & Small & Medium & Medium \\
\hline & Technical & 39.20 & 12.00 & 19.20 & Medium & Small & Small \\
\hline \multirow{3}{*}{$\begin{array}{c}\text { Level } 2 \\
\text { (Economic) }\end{array}$} & Cost & 0.60 & 33.00 & 51.30 & Small & Medium & Large \\
\hline & Financial incentives & 23.40 & 92.40 & 29.70 & Medium & Large & Medium \\
\hline & Installation time & 22.50 & 59.70 & 21.30 & Medium & Large & Medium \\
\hline \multirow{2}{*}{$\begin{array}{c}\text { Level } 2 \\
\text { (Environmental) }\end{array}$} & $\begin{array}{c}\text { In-use environmental } \\
\text { performance }\end{array}$ & 17.60 & 21.40 & 16.00 & Small & Medium & Small \\
\hline & Recycled content & 17.60 & 21.40 & 16.00 & Small & Medium & Small \\
\hline \multirow{2}{*}{ Level 2 (Social) } & Societal benefits & 4.40 & 4.40 & 1.20 & Small & Small & Small \\
\hline & Organisational benefits & 4.40 & 4.40 & 1.20 & Small & Small & Small \\
\hline \multirow{2}{*}{ Level 2 (Technical) } & Installation & 10.00 & 25.60 & 2.00 & Small & Medium & Small \\
\hline & Operation & 10.00 & 25.60 & 2.00 & Small & Medium & Small \\
\hline \multirow{3}{*}{ Level 3 (Cost) } & Investment cost & 27.30 & 73.20 & 9.90 & Medium & Large & Small \\
\hline & O\&M cost & 17.40 & 5.40 & 23.70 & Small & Small & Medium \\
\hline & Payback period & 45.00 & 78.90 & 13.50 & Medium & Large & Small \\
\hline Level 3 (In-use & Reduction of energy & 6.00 & 10.00 & 25.00 & Small & Small & Medium \\
\hline
\end{tabular}




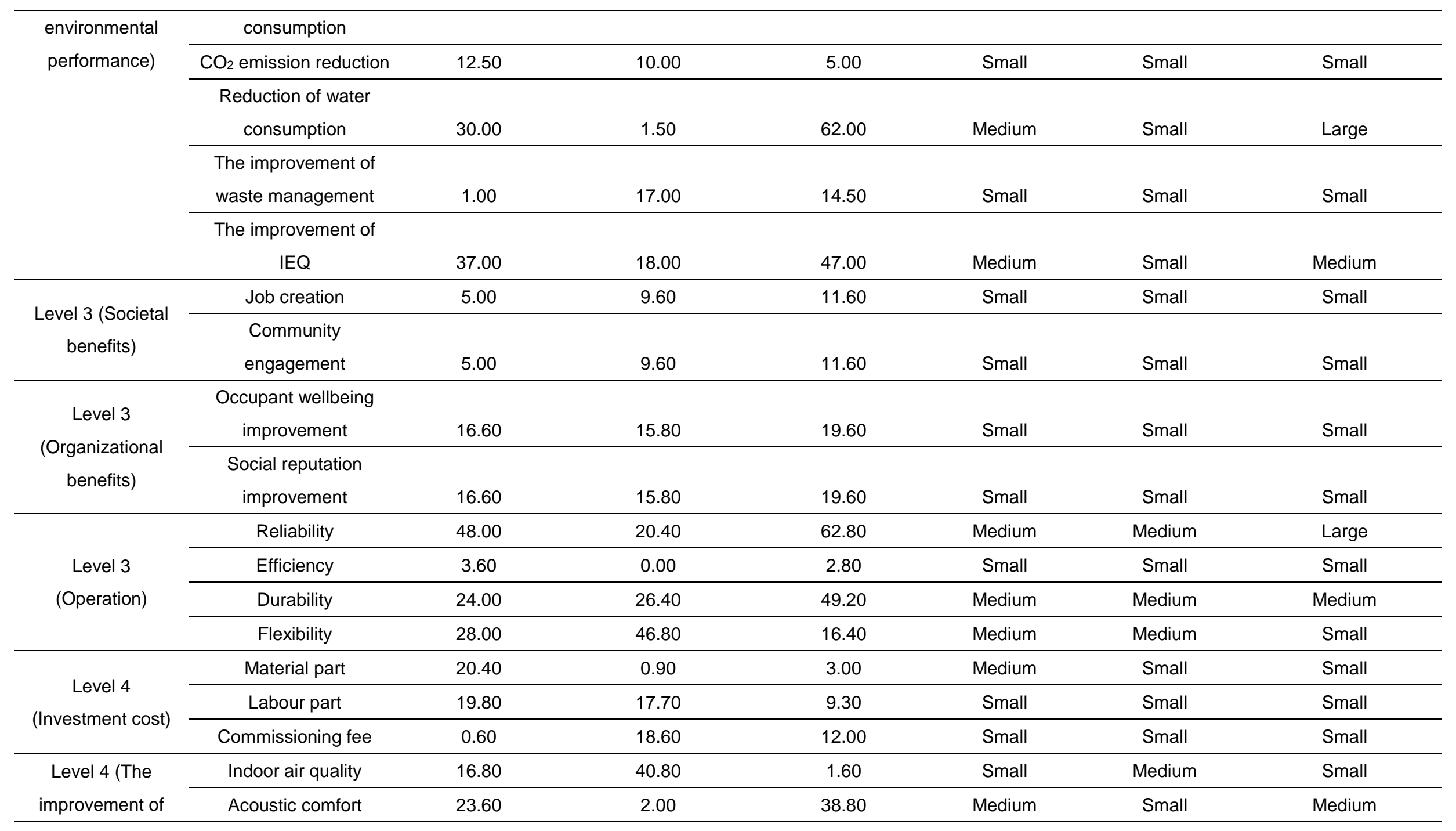




\begin{tabular}{|c|c|c|c|c|c|c|c|}
\hline \multirow[t]{2}{*}{ IEQ) } & Visual comfort & 48.40 & 79.60 & 27.60 & Medium & Large & Medium \\
\hline & Thermal comfort & 55.20 & 36.40 & 68.00 & Large & Medium & Large \\
\hline \multirow{3}{*}{$\begin{array}{c}\text { Level } 4 \text { (Occupant } \\
\text { wellbeing } \\
\text { improvement) }\end{array}$} & Psychological & & & & & & \\
\hline & wellbeing & 1.00 & 4.60 & 5.80 & Small & Small & Small \\
\hline & $\begin{array}{c}\text { Productivity and } \\
\text { performance }\end{array}$ & 1.00 & 4.60 & 5.80 & Small & Small & Small \\
\hline
\end{tabular}

